\title{
Pricing and Return Policies in a Competitive Market: A Consumer-Valuation Based Analysis with Valuation Uncertainties
}

\author{
Huifang Jiao ${ }^{1}$, Xuan Wang ${ }^{1, *}$, Chi To $\mathrm{Ng}^{2}$ and Lijun Ma ${ }^{1}$ \\ 1 Department of Management Science, College of Management, Shenzhen University, Shenzhen 518060, China; \\ jiaohf@szu.edu.cn (H.J.); ljma@szu.edu.cn (L.M.) \\ 2 Logistics Research Centre, Department of Logistics and Maritime Studies, The Hong Kong Polytechnic \\ University, Hung Hom, Kowloon, Hong Kong, China; lgtctng@polyu.edu.hk \\ * Correspondence: wangx66@szu.edu.cn
}

Citation: Jiao, J.; Wang, X.; Ng, C.T.; $\mathrm{Ma}, \mathrm{L}$. Pricing and Return Policies in a Competitive Market:

A Consumer-Valuation Based Analysis with Valuation Uncertainties. Sustainability 2021, 13, 1432.

https://doi.org/10.3390/su13031432

Academic Editor: Ermanno C. Tortia Received: 2 December 2020

Accepted: 20 January 2021

Published: 29 January 2021

Publisher's Note: MDPI stays neutral with regard to jurisdictional clai$\mathrm{ms}$ in published maps and institutional affiliations.

Copyright: (C) 2021 by the authors. Licensee MDPI, Basel, Switzerland. This article is an open access article distributed under the terms and conditions of the Creative Commons Attribution (CC BY) license (https:// creativecommons.org/licenses/by/ $4.0 /)$.

\begin{abstract}
In this study, we develop a series of consumer-valuation-based models to investigate the pricing and return policies of the sellers in a competitive e-commerce market. Differing from the competition models in literature, a novel two-dimensional valuation structure is built, which considers the valuations of a consumer on two products and the valuation differentiation of all consumers on each product. We consider both monopoly and duopoly (competitive) markets. In each market, two models are respectively developed, one with and one without the return policies. We derive the solutions for the four models, and conduct some analytical and numerical investigations. The results show that return policy with a partial refund is always chosen by the sellers in both monopoly and duopoly markets. Return policy benefits the seller in a monopoly market, but may not benefit the sellers in a duopoly market. In the duopoly models, one seller can be considered as a monopoly seller who meets a new competitor. Our results show that the monopoly seller will reduce its price by no more than $20 \%$ when there comes a competitor, and, counter-intuitively, it will meanwhile adopt a severer return policy to the consumers .
\end{abstract}

Keywords: pricing; return policy; consumer valuation; competition

\section{Introduction}

E-commerce has been rapidly developed in the recent 20 years. The most representative enterprises are eBay in America and Alibaba in China. Speaking of e-commerce, two phenomena are non-negligible. One is the intense competition of all e-sellers due to the low threshold for sellers to join the e-market. It only takes few hours to open one's own shop on the website. The other one is the great amount of consumer returns, because consumers can only observe the information of a product online and ascertain their valuations on the product after they receive it in an express box. This kind of products, whose valuations can only be ascertained after consumption, is called "experience goods" in economics. A return policy may be adopted by the sellers to manage consumer returns.

The intense competition and the return policy for consumer returns form a dilemma to the sellers. In e-commerce, consumers are sensitive to the severity of return policy because they want to return easily after purchase. A high level of severity of return policy may hold back the consumers from purchasing, which can be fatal to a seller in an intense competitive market. However, a lenient return policy may cause a loss to the seller because it leads to more returns and less revenue.

Environmentally, consumer returns cause negative impacts on our living world. Returned goods will incur redundant delivery cost. Moreover, many returned goods are taken as wasted goods which end in environmentally harmful landfills. Optoro, a company who provides return solutions for its clients such as Best Buy, Jet, Staples, etc, reports that 
about five billion pounds of returned goods end in landfills as garbage annually in United States. Therefore, managing returns in e-commerce is significant in sustainability area.

However, return policy matters in consumer satisfaction. A survey conducted by Narvar, a platform who offers post-purchasing consumer experience, shows that $67 \%$ products are deterred from buying because of the return fee. So, many e-commerce companies will adopt lenient return policy in competition in case that the consumers change to buy from its competitor. On contrary, some researches (such as [1,2]) in literature show that a severe return policy can be sustained in competition under certain conditions.

The purpose of our research is to investigate the pricing policy and return policy in a competitive e-commerce market in a novel competition setting, where the sellers compete with each other in a market with the consumers' valuation differentiation. More precisely, we develop a novel model involving a two-dimensional valuation structure, which considers one consumer's valuations on two products and the differentiation of all consumers' valuations on each product. This consumer-valuation-based setting is based on that the consumers' purchasing experience/valuations online will differ because of many aspects, such as music and colors in the website [3], information design, visual design, and navigation design, etc. [4]. Thus, a consumer-valuation-based analysis has realistic basis and is reasonable and valuable.

In the literature, there have been researches on consumer-valuation-based return policy both in monopoly and competitive market, such as [2,5]. However, our research is unique in considering the consumer-valuation-based analysis in a two-dimensional structure.

We focus on the consumers' purchasing and return behaviors based on their product valuations. Based on the background above, we summarize our research questions (RQs) as follows: (RQ1) Will a seller adopt return policy in a monopoly or duopoly market? (RQ2) What are the effects of return policy on a seller's price and revenue in a monopoly or duopoly market? (RQ3) What are the effects of competition on a seller's price, revenue and return policy, comparing the changes from a monopoly market to a duopoly market?

In our RQs, the return policy is considered as a decision of the sellers. However, in some countries, the return policy is not decided by the sellers, but is determined by the consumer protection laws. For example, in Europe, there are laws named The Directive on Consumer Rights (2011/83/EU), which require that the e-commerce sellers must accept consumer returns within 14 days after the product sales and must return all the money to the consumers. In practice, the consumer protection laws differ from country to country. We can observe that JD.com, one of the biggest e-commerce sellers in China, insists that a part of products cannot be returned without reasons to avoid loss because these products cannot be recycled properly. The consumer returns with no reasons in e-commerce do harm to both the sellers' profits and the environment. Thus, in this paper, we consider the situation that the return policy is the sellers' decision, without the restriction of laws.

To achieve our research aim, four models are developed: two monopoly models, one with and one without return policy; and two duopoly models, one with and one without return policy. The two monopoly models are formulated as nonlinear programming models, while the two duopoly models are investigated using game theory. The severity of return policy is characterized by the refund proportion to consumers if a product is returned.

We provide the optimal or Nash Equilibrium solutions for the four models and conduct some analytical and numerical studies to answer the RQs. Our results show that in both monopoly and duopoly markets, the sellers will adopt return policy (RQ1). In the monopoly market, adopting return policy does not affect the seller's price but brings the seller more revenue; in the duopoly market, return policy leads to lower prices and possibly lower revenues (RQ2). We consider one seller in the duopoly market as the seller in the monopoly market who meets a new competitor. The seller's price and revenue in the duopoly market are lower than those in the monopoly market; the price in the duopoly market cannot be lower than $80 \%$ of the optimal price in the monopoly market; additionally, the severity of return policy in the duopoly market is higher than that in the monopoly market (RQ3). These results provide management insights that a monopoly seller may 
reduce its price by no more than $20 \%$ when there comes a competitor, and the return policy can be severer in a competitive market than that in a monopoly market.

We present a literature review in Section 2. In Sections 3 and 4, we study the pricing and return policies in monopoly and duopoly markets, respectively. Analytical and numerical studies are conducted in Sections 5 and 6. The conclusions are given in Section 8.

\section{Literature Review}

Experience goods in e-commerce lead to consumers' post-purchase valuation uncertainty, so consumers may return the product after purchasing. Return policy is offered to the consumers to manage their returns. In the literature, there is a stream on consumer return policy considering money back (refund) in a monopoly market. Ref. [6] treat the refund decision as dichotomous: whether or not to offer a full $(100 \%)$ refund. Their research shows that offering a full refund can be more profitable than selling without returns under certain conditions. Ref. [7] shows that full refund policy is more profitable when consumers are highly risk averse or selling costs are high. Ref. [8] develop a model that allows the seller to reduce returns by altering the 'hassle' cost to the consumer for returning the product. Ref. [9] explore the overall effects of allowing refund in advance sales and find that allowing a refund is optimal for products with a small profit margin and small strategic market size.

In these models, a seller offers either no refund or a full refund for a product. However, the seller may retain a portion of the price paid originally by consumers if returns are allowed. Ref. [10] develop a model of partial refund to control inappropriate returns by opportunistic consumers. Based on this research, Ref. [11] further study the distinction among 'no questions asked policy', 'no refunds' and 'verifiable problems only policy', and they find that the first policy is the optimal solution to handle consumer opportunism. Ref. [5] introduce a newsvendor model with returns and opportunistic consumers. They exclusively identify the impact of return type as abused or normal. In our study, the severity of return policy is measured by the proportion of refund to the consumers. A $100 \%$ proportion represents a full refund policy and a proportion less than $100 \%$ represents a partial refund policy.

For the consumers, return policy means a protection for their purchasing decisions. Using a mechanism design approach, Ref. [12] show that the optimal mechanism is a menu of expiring refund contracts when consumers observe their true valuations at different time epochs. However, Ref. [13] show that with finite inventory, a menu of return policies that serves the entire population is no longer the optimal selling policy. Meanwhile, the seller is able to reduce the post-valuation uncertainty by providing information. Ref. [14] find that even if it is possible to eliminate returns without cost through the provision of information about the fit between consumer preferences and product characteristics, returns can nevertheless be part of the optimal product sales process. Our research analyses the impact of post-valuation uncertainty on the seller's revenue in monopoly and duopoly markets, by assuming a post-purchase uncertain component in consumers' valuations.

In addition to protecting consumers from post-valuation uncertainty, return policy is also useful to signal the product quality when consumers face a market with unknown product quality. Refs. [15-18] comprise a stream of study demonstrating that return policy serves as providing an effective tool for high-quality sellers to distinguish themselves from the others and it costs more for the sellers whose product quality is lower to offer generous return policy. Another stream of study [19-22] shows that a more generous return policy boosts consumer demand and increases seller's profit. To focus on our research aim, we assume that the seller provides no defective products that enable consumers to be satisfied in quality.

The literature above is on the return policy in a monopoly market. While in a competitive market, more studies are needed about how return policy works and whether the partial refund should be sustained. Ref. [1] builds on [23]'s model to show that the sellers in a duopoly market should adopt identical partial refund policies for advanced sales only 
when the capacity is small such that the efficiency-improving effect is dominant. Ref. [2] use a Salop circle model to show that partial refund can be sustained in a competitive environment and the return policy is severer when the fit problem between products' attributes and consumers' preferences is more serious.

There is another stream of literature on the return policy throughout the supply chain. Ref. [24] provides a review of the literature about return contracts between the retailer and the manufacturer including buy-back contract, quantity-flexibility contract and sales-rebate contract. Ref. [25] propose a target rebate contract which is Pareto improving by providing an incentive to the retailer to increase its effort of reducing false failure returns. Ref. [26] investigate the adjustment of buyback contracts under different risk levels of consumers' valuations. Ref. [27] studies the impacts of consumer returns on supply chain performance when the consumers exhibit valuation uncertainty and the manufacturer is confronted with demand uncertainty. Ref. [28] studies the pricing and return policies to achieve channel coordination in a multi-retailer environment.

There are also researches on other ways of dealing with returns, such as consumer's P2P market, or buy-online-and-return-in-store (BORS), etc. Ref. [29] investigate the effect of the P2P market on the seller's optimal return policy when consumers are strategic and uncertain about their valuations. Ref. [30] find that in a competitive market with two supply chains, the BORS will be offered by the two retailers in nearly all conditions.

In sum, the main contribution of our work is the new competitive pricing and return policy models based on consumers' valuations under uncertainty. To the best of our knowledge, it is the first to incorporate one consumer's independent valuations on different products with all consumers' aggregate valuations on one product. It is worth mentioning that out of the four models we present, one is about pricing policy in a duopoly market without return policy. This model is a new pure price competition, which generates new insights on price decision of a monopolist facing a new joiner in the market.

\section{Pricing Policy in a Monopoly Market}

\subsection{Assumptions and Notations}

This section considers the pricing and return decisions of a monopolistic seller. The seller sells an experience good (product) to the consumers, and reserves the right to retain a portion of the price paid originally if a consumer returns the product. The seller makes two decisions: adopt a return policy or not (if he adopts the return policy, a refund proportion $\alpha$ will be given to the consumers if the product is returned, $0 \leq \alpha \leq 1)$, and the price, $p$. The returned product has no salvage value to the seller. The seller's goal is to maximize the expected revenue.

The consumers are heterogeneous in their intrinsic preferences, which is represented by a pre-valuation $v$, and $v$ is uniformly distributed over $[0, V]$. A post-purchase valuation uncertainty $\epsilon$ is observed only after a purchase is made, $\epsilon \sim U[-\delta, \delta]$. Therefore, the consumer's post-valuation is $v+\epsilon$. The value of $\delta$ is assumed to be less than $\frac{V}{2}$ following the assumption in [2]. If one consumer purchases the product at price $p$, his utility is $v+\epsilon-p$.

Consumers make two decisions sequentially. Initially, they decide whether to purchase the product. If so, they decide whether to keep it after their valuation uncertainty is realized. Without loss of generality, we assume that the consumers have no hassle cost to make a return. They seek to maximize the expected utility of their own. The total volume of all consumers is normalized to one and one consumer will buy no more than one product.

The decision procedures are as follows. First, the seller determines price $p$, return policy $W$ (with) or $O$ (without), and refund proportion to consumers $\alpha$ if he adopts a return policy. Second, consumers make purchasing decisions based on their expected utility. Then the market demand $D$ is realized. Third, each consumer who has bought the product decides whether to keep or return it. Till then, the revenue of the seller is finalized. Additionally, we focus on revenue management in the marketing process, so the production cost is out of our consideration. All the notations used in this chapter are presented in Table 1. 
Table 1. Notations used throughout this study.

\begin{tabular}{lll}
\hline & $p$ & Price of product \\
& $\alpha$ & Refund proportion if return policy is adopted \\
Notations & $c$ & Return penalty to consumers, and $c=(1-\alpha) p$ \\
& $v$ & Pre-purchase valuation of consumer on product, $v \sim U[0, V]$ \\
& $\epsilon$ & Valuation uncertainty of consumer after purchase, $\epsilon \sim U[-\delta, \delta]$ \\
& $v+\epsilon$ & Post-purchase valuation of consumer on product \\
\hline \multirow{3}{*}{$\begin{array}{l}\text { Superscript } \\
\text { and }\end{array}$} & $i$ & Seller number, $i=1$ for Seller 1 and $i=2$ for Seller 2 \\
Subscript & $m, d$ & Market type, ' $m$ ' represents 'monopoly' and ' $d$ ' represents 'duopoly' \\
& $j, k$ & Return policy, 'O' $O$ ' means 'without' and ' $W$ ' means 'with' \\
& & $j, k=O$ or $W$
\end{tabular}

The next two Sections 3.2 and 3.3 are the studies on the monopoly models with and without return policy. Then Section 3.4 presents the comparison of the two monopoly models.

These models are designed for achieving our research aims. Here, we explain why we design those four models: the two models considering pricing policy without/with return policy in monopoly market, which are named as Model $M_{m}^{O}$ and Model $M_{m}^{W}$, respectively; and the two models considering pricing policy without/with return policy in duopoly (competitive) market, named as Model $M_{d}^{O}$ and $M_{d}^{W}$. The results of the four models can achieve our three research aims in the following way:

(1) Our first research aim is to investigate the return policy adoption in monopoly and duopoly market (RQ1). The results of the two models with return policy in monopoly and duopoly market (Models $M_{m}^{W}$ and $M_{d}^{W}$ ) can tell that if the sellers should choose to adopt the return policy or not.

(2) Our second research aim is to investigate the effects of return policy on the seller's price and revenue (RQ2). This aim can be achieved by comparing the models without return policy and with return policy in monopoly or duopoly market, that is, the comparison of Models $M_{m}^{O}$ and $M_{m}^{W}$, and the comparison of Models $M_{d}^{O}$ and $M_{d}^{W}$.

(3) Our third aim is to investigate the impact of competition (RQ3). This aim can be achieved by comparing the models in monopoly and duopoly markets without or with return policy, that is, the comparison of Models $M_{m}^{O}$ and $M_{d}^{O}$, and the comparison of Models $M_{m}^{W}$ and $M_{d}^{W}$.

\subsection{Monopoly Model without Return Policy}

In this subsection, we first develop a simple monopoly model without return policy, which means the seller does not accept returned products. The seller sets the price $p$ and only the consumers with non-negative expected utility will buy the product. With $\epsilon \sim U[-\delta, \delta]$, consumer's expected utility is $v+E(\epsilon)-p=v-p$, thus the threshold to buy the product is $v=p$. For description, we denote the probability density function of $v$ as $f(v)$. The realized demand is $\int_{p}^{V} f(v) d v=\int_{p}^{V} \frac{1}{V} d v=\frac{V-p}{V}$. The seller's revenue without return policy is

$$
\Pi_{m}^{O}=p \int_{p}^{V} f(v) d v=\frac{p(V-p)}{V} .
$$

The following lemma characterizes the optimal price of the monopolistic seller without return policy.

Lemma 1. The optimal price of monopolist without return policy is $\left(p_{m}^{O}\right)^{*}=\frac{V}{2}$ and the maximum revenue is $\left(\pi_{m}^{O}\right)^{*}=\frac{V}{4}$.

\subsection{Monopoly Model with Return Policy}

In this subsection, we extend the analysis to the model with return policy, in which the seller offers to accept consumers' returns with a refund proportion $\alpha$. Consumer's utility may be one of the following three cases. If they purchase and keep the product, the utility 
is the post-valuation minus price, that is, $v+\epsilon-p$. If they purchase but return the product, the utility is the returned money minus price, $\alpha p-p$. If they do not purchase, they receive zero utility.

To identify those consumers who may return products back after purchase, we choose one consumer with pre-valuation $v^{\prime}$. It is clear that consumers keep products with $v^{\prime}+\epsilon-$ $p>\alpha p-p$, that is, $v^{\prime}>\alpha p-\epsilon$. With $\epsilon \sim U[-\delta, \delta]$, a threshold $v_{r}$ is defined on consumers' return and $v_{r}=\alpha p+\delta$.

When $v^{\prime}$ exceeds $v_{r}$, the consumer never returns because his pre-valuation is high enough to keep the product ( $v^{\prime}>\alpha p-\epsilon$ anyway), and return policy is not needed to them. The consumer's utility remains to be $v^{\prime}+E(\epsilon)-p=v^{\prime}-p$.

When $v^{\prime}$ is smaller than $v_{r}$, we rewrite $v^{\prime}<\alpha p-\epsilon$ to $\epsilon<\alpha p-v^{\prime}$. The consumers with $\epsilon<\alpha p-v^{\prime}$ will return the product and gain $\alpha p-p$, and the consumers with $\epsilon \geq \alpha p-v^{\prime}$ will keep the product and gain $v+\epsilon-p$. Thus, the expected utility in the return range $2 \delta$ is $\int_{\alpha p-v^{\prime}}^{\delta} \frac{v^{\prime}+\epsilon-p}{2 \delta} d \epsilon+\int_{-\delta}^{\alpha p-v^{\prime}} \frac{\alpha p-p}{2 \delta} d \epsilon$.

Thus, if the purchase is made, the expected utility is

$E U= \begin{cases}\alpha p-p, & \text { when } v^{\prime}<\alpha p-\delta \\ \int_{\alpha p-v^{\prime}}^{\delta} \frac{v^{\prime}+\epsilon-p}{2 \delta} d \epsilon+\int_{-\delta}^{\alpha p-v^{\prime}} \frac{\alpha p-p}{2 \delta} d \epsilon=\frac{\left(v^{\prime}+\delta-\alpha p\right)^{2}}{4 \delta}+\alpha p-p, & \text { when } \alpha p-\delta \leq v^{\prime}<v_{r} \\ v^{\prime}+E(\epsilon)-p=v^{\prime}-p, & \text { when } v^{\prime} \geq v_{r} .\end{cases}$

Consumers purchase products when $E U$ is non-negative. When $v^{\prime}<\alpha p-\delta$, $E U=\alpha p-p<0$, the consumers will not buy the product. When $\alpha p-\delta \leq v^{\prime}<v_{r}$, we can establish a pre-valuation threshold to buy the product, $v_{b}\left(\left.E U\right|_{v=v_{b}}=0\right)$. The realized buyers are consumers whose pre-valuations are not less than $v_{b}$, and $v_{b}=\alpha p-\delta+$ $2 \sqrt{\delta p(1-\alpha)}$. When $v^{\prime} \geq v_{r}$, the threshold of consumers to buy the product is $v^{\prime}=p$.

Moreover, if $p>v_{r},\left.E U\right|_{v^{\prime}=v_{r}}=v_{r}-p<0$. Only the consumers with $v^{\prime}>p$ will buy the product, and they will not return the product because $p>v_{r}$. The model becomes the same with the model without return policy. We show in the proof for Lemma 2 that the seller will make $p \leq v_{r}$ to gain a higher revenue, and the consumers with $v^{\prime}>v_{b}$ will buy the product.

Thus, the realized demand is $\int_{v_{b}}^{V} f(v) d v$. The expected returned amount of products is $\int_{v_{b}}^{\min \left\{v_{r}, V\right\}} \frac{v_{r}-v}{2 \delta} f(v) d v$. The seller returns a refund proportion of $\alpha p$ to consumers who purchase and return. The seller's revenue with return policy is

$$
\Pi_{m}^{W}=p \int_{v_{b}}^{V} f(v) d v-\alpha p \int_{v_{b}}^{\min \left\{v_{r}, V\right\}} \frac{v_{r}-v}{2 \delta} f(v) d v .
$$

The following lemma characterizes the optimal price and return policy (refund proportion) of a monopolistic seller considering return policy.

Lemma 2. The optimal price and refund proportion of the monopolistic seller are $\left(p_{m}^{W}\right)^{*}=\frac{V}{2}$ and $\left(\alpha_{m}^{W}\right)^{*}=1-\frac{\delta}{2 V}$. The maximum revenue is $\left(\pi_{m}^{W}\right)^{*}=\frac{V}{4}+\frac{\delta^{2}}{16 V}$.

This result is in accord with the results of $[10,11]$. Even though some assumptions in our models are different, we can tell that the results of the optimal price and return policy are actually in a quite similar formats with those in the literature. The main difference is that in their models, there is a parameter which indicates the dis-match probability of the consumer's valuation and the product property. The consumer will get zero value from the product if there is dis-matching. However, we model the dis-matching by the post-valuation uncertainty $\epsilon$. The consumer will get $v+\epsilon-p$ if there is dis-matching. Thus, the results of the optimal price and return policy of our models differ from those in literature to a certain level, but our results are still in similar formats. 


\subsection{Comparison of the Two Monopoly Models}

By observing the optimal solutions of the two monopoly models, the following proposition demonstrates that in a monopoly market, return policy always benefits the seller.

Proposition 1. The optimal prices of the monopolistic seller with and without return policy are equal, that is, $\left(p_{m}^{O}\right)^{*}=\left(p_{m}^{W}\right)^{*}=\frac{V}{2}$. The optimal refund proportion to consumers $\alpha$ is smaller than $100 \%$. Return policy brings the seller incremental revenue $\frac{\delta^{2}}{16 V}$, which increases in $\delta$.

Proposition 1 indicates that the seller will always allow returns and provide a partial refund to the consumers. The seller's profit increases in the post-purchase uncertainty $\delta$. Meanwhile, the refund proportion $\alpha$ decreases as $\delta$ increases according to Lemma 2. These results show that as the consumers' post-purchase uncertainty $\delta$ increases, the firm will decrease the refund proportion to the consumers and the firm's revenue increases consequently.

\section{Pricing Policy in a Duopoly Market}

Now, we turn to the duopoly models. These models are developed to study the prices and return policies in a competitive market. Two substitute products, which are experience goods, are respectively sold by two sellers. The two products are not perfect substitutes, which means one consumer may assess different valuations on them. One consumer's individual pre-valuations on these two substitutable are denoted by $v_{1}, v_{2}$, respectively. We assume that they are uniformly distributed and independent, that is

$$
f\left(v_{1}, v_{2}\right)= \begin{cases}f\left(v_{1}\right) f\left(v_{2}\right)=\frac{1}{V_{1} V_{2}}, & \text { when } 0 \leq v_{1} \leq V_{1} \text { and } 0 \leq v_{2} \leq V_{2} \\ 0, & \text { otherwise }\end{cases}
$$

The uniform distribution is normally used in models considering consumer valuations. For example, Ref. [31] also use the two dimensional structure capturing the two consumer valuations in two periods.

Post-purchase valuation uncertainties exist, which are denoted by $\epsilon_{1}, \epsilon_{2}$, and $\epsilon_{1} \sim U\left[-\delta_{1}, \delta_{1}\right]$ and $\epsilon_{2} \sim U\left[-\delta_{2}, \delta_{2}\right]$. The same as in the monopoly model, the values of $\delta_{1}$ and $\delta_{2}$ are assumed to be less than $V_{1} / 2$ and $V_{2} / 2$, respectively. $0<p_{1} \leq V_{1}$ and $0<p_{2} \leq V_{2}$ are assumed to ensure the survivals of the two products in the market, for otherwise, no consumers will buy the product.

The two products are priced at $p_{1}, p_{2}$ by the two sellers. The sellers' decisions include the prices of products $p_{i}(i=1,2)$, return policies ("without" or "with") and refund proportions to consumers $\alpha_{i}(i=1,2)$ if return policies are adopted. Both sellers seek to maximize their expected revenues.

Each consumer's decisions are as follows. Initially, he decides to buy from Seller 1, or buy from Seller 2, or leave the market. If he makes a purchase, he decides whether to keep the product based on his post-valuation. Each consumer wants to maximize individual expected utility. The total volume of consumers is normalized to one and one consumer will buy no more than one product.

This model captures both aggregate consumers' valuations on each product and one consumer's independent valuations on two products. It has a feature of two-dimension. Depending on the sellers' prices and return policies, consumers making purchase decisions allow us to define the market demands of both sellers. After consumers decide whether to keep the product or return it, the revenues of sellers are realized. Our aim is to find the Nash Equilibrium in the duopoly game.

\subsection{Duopoly Model without Return Policy}

In this subsection, we first investigate the duopoly model without return policy. Since prices are the only decision variables, the duopoly model is a pure price competition 
model. Based on the consumers' valuations, the two-dimensional valuation-based model is developed. Figure 1 demonstrates the demands realization in this model.

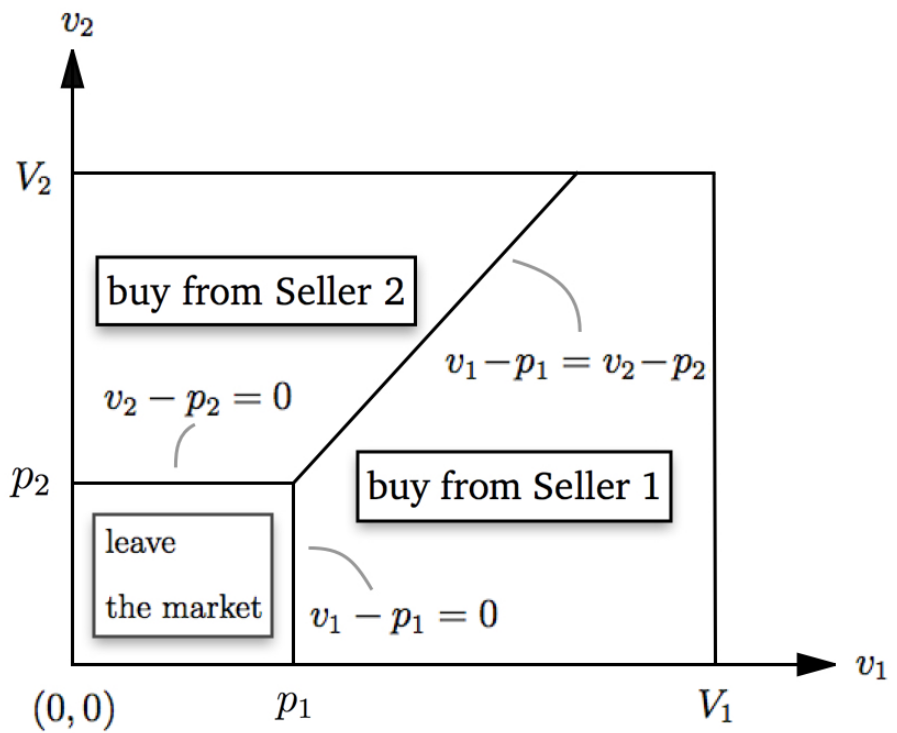

Figure 1. Market division in a duopoly market without return policy.

As mentioned before, each consumer gives two valuations $v_{1}, v_{2}$ to two experience goods (products) respectively. Observing the prices $p_{1}, p_{2}$ offered by two sellers, he has two expected utilities from purchasing the two products respectively: $v_{1}+E\left(\epsilon_{1}\right)-p_{1}=$ $v_{1}-p_{1}, v_{2}+E\left(\epsilon_{2}\right)-p_{2}=v_{2}-p_{2}\left(\epsilon_{1} \sim U\left[-\delta_{1}, \delta_{1}\right]\right.$ and $\left.\epsilon_{2} \sim U\left[-\delta_{2}, \delta_{2}\right]\right)$. The consumer wants to maximize his utility, so he compares the three utilities: $v_{1}-p_{1}$ (purchasing from Seller 1$), v_{2}-p_{2}$ (purchasing from Seller 2 ) and 0 (leaving the market). This three utilities form three boundaries $v_{1}-p_{1}=v_{2}-p_{2}, v_{1}-p_{1}=0$ and $v_{2}-p_{2}=0$ between consumers with different choices. Hence, from Figure 1, the demands of the two sellers are determined. Multiplying prices, the revenues of the two sellers are

$$
\begin{aligned}
& \Pi_{d 1}^{O}=p_{1} \int_{p_{1}}^{V_{1}} \int_{0}^{\min \left\{v_{1}-p_{1}+p_{2}, V_{2}\right\}} f\left(v_{1}, v_{2}\right) d v_{2} d v_{1}, \\
& \Pi_{d 2}^{O}=p_{2} \int_{p_{2}}^{V_{2}} \int_{0}^{\min \left\{v_{2}-p_{2}+p_{1}, V_{1}\right\}} f\left(v_{1}, v_{2}\right) d v_{1} d v_{2} .
\end{aligned}
$$

By the calculations of giving any $p_{1}$ to find the optimal $p_{2}$ and the same in reverse, we find that the prices of two sellers in Nash Equilibrium are the solutions to the following equation set. The proof for equation set 7 is given in the Appendix A.

$$
\left\{\begin{array}{l}
\left(V_{1}-2 p_{1}\right) \min \left\{V_{1}-p_{1}+p_{2}, V_{2}\right\}=\int_{p_{2}}^{\min \left\{V_{1}-p_{1}+p_{2}, V_{2}\right\}}\left(v_{2}-p_{2}\right) d v_{2} \\
\left(V_{2}-2 p_{2}\right) \min \left\{V_{2}-p_{2}+p_{1}, V_{1}\right\}=\int_{p_{1}}^{\min }\left\{V_{2}-p_{2}+p_{1}, V_{1}\right\}\left(v_{1}-p_{1}\right) d v_{1}
\end{array}\right.
$$

We denote the equilibrium prices as $p_{d 1}^{O}, p_{d 2}^{O}$, whose close-form solutions are too complex to be given. However, we can find a range in which they exist. It is obvious that $V_{i}-2 p_{d i}^{O}>0(i=1,2)$, so the equilibrium price $p_{d i}^{O}$ is smaller than $\frac{V_{i}}{2}$. Additionally, Figure 2 shows that given any $p_{1}$, there will be an optimal $p_{2}$ and the same in reverse $p_{1}$, which form the functions $p_{2}\left(p_{1}\right)$ and $p_{1}\left(p_{2}\right)$ (the two full lines). It is proved that $\frac{\partial p_{1}\left(p_{2}\right)}{\partial p_{2}}>0, \frac{\partial p_{2}\left(p_{1}\right)}{\partial p_{1}}>0$, $\frac{\partial^{2} p_{1}\left(p_{2}\right)}{\partial p_{2}^{2}}<0$, and $\frac{\partial^{2} p_{2}\left(p_{1}\right)}{\partial p_{1}^{2}}<0$. The two functions $p_{1}\left(p_{2}\right)$ and $p_{2}\left(p_{1}\right)$ are concave, so we can draw the two dashed lines which cross at the point $\left(\frac{2 V_{1}}{5}, \frac{2 V_{2}}{5}\right)$. Thus, we obtain that $p_{d i}^{O}$ is larger than $\frac{2 V_{i}}{5}(i=1,2)$. 


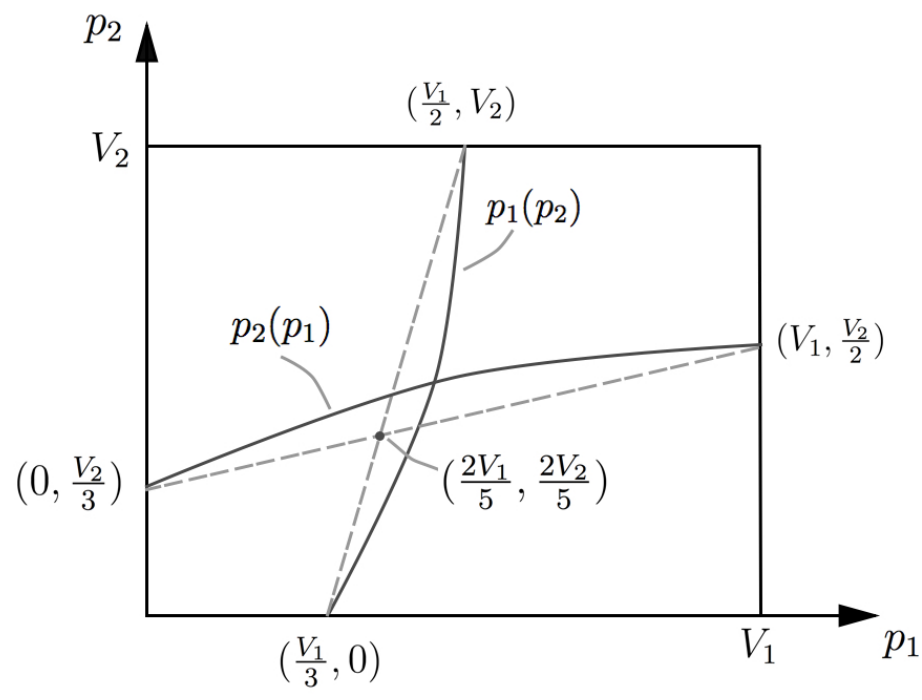

Figure 2. The ranges of the prices in Nash Equilibrium in the duopoly model.

Lemma 3. In a duopoly market, the equilibrium prices of two sellers without return policy are $p_{d 1}^{O}$ and $p_{d 2}^{O} . p_{d i}^{O}$ is larger than $\frac{2 V_{i}}{5}$ and smaller than $\frac{V_{i}}{2}, i=1,2$.

Next, we consider the duopoly model with return policy. Then we will compare the prices and profits of the two sellers in the duopoly models with and without return polices, to reveal the impact of return policies.

\subsection{Duopoly Model with Return Policy}

In the duopoly model with return policy, both sellers not only decide their prices $p_{1}, p_{2}$, but also settle on whether to adopt return policies. They both may adopt or abandon the return policy. Hence the game shows up as in Table 2.

Table 2. The game in a duopoly market.

\begin{tabular}{lll}
\hline Seller 2 $\backslash$ Seller 1 & without & with \\
\hline without & $\left(\Pi_{d 1}^{O O}, \Pi_{d 2}^{O O}\right)$ & $\left(\Pi_{d 1}^{W O}, \Pi_{d 2}^{W O}\right)$ \\
with & $\left(\Pi_{d 1}^{O W}, \Pi_{d 2}^{O W}\right)$ & $\left(\Pi_{d 1}^{W W}, \Pi_{d 2}^{W W}\right)$ \\
\hline
\end{tabular}

If a seller adopts the return policy, he decides the refund proportion to consumers if they return. We still employ $\alpha_{i}(i=1,2)$ to denote the two sellers' refund proportions to the consumers.

Each consumer has two valuations $v_{1}, v_{2}$ on the two experience goods. He observes two prices $p_{1}, p_{2}$, probably with return policy $\alpha_{1}, \alpha_{2}$. The consumer's expected utilities for "with" and "without" return policies are different. For the convenience of description, we denote the expected utility of the consumer with his valuation $v_{i}$ without return policy as $u_{i}^{O}\left(v_{i}\right)$ and the expected utility with return policy as $u_{i}^{W}\left(v_{i}\right)$. The same as in Section 3 , we have

$$
\begin{gathered}
u_{i}^{O}\left(v_{i}\right)=v_{i}+E\left(\epsilon_{i}\right)-p_{i}=v_{i}-p_{i}, \\
u_{i}^{W}\left(v_{i}\right)= \begin{cases}\frac{\left(v_{i}+\delta_{i}-\alpha_{i} p_{i}\right)^{2}}{4 \delta_{i}}+\alpha_{i} p_{i}-p_{i} & \text { when } v_{i}<v_{r}, \\
v_{i}-p_{i} & \text { when } v_{i} \geq v_{r} .\end{cases}
\end{gathered}
$$

The consumer maximizes his utility by comparing $u_{1}^{j}\left(v_{1}\right), u_{2}^{k}\left(v_{2}\right)$ and $0(j, k=0$ or $W)$. Again, the three utilities generate three boundaries that divide consumers into three parts: buy from Seller 1, buy from Seller 2, leave the market. The boundaries are $u_{1}^{j}\left(v_{1}\right)=u_{2}^{k}\left(v_{2}\right), u_{1}^{j}\left(v_{1}\right)=0$ and $u_{2}^{k}\left(v_{2}\right)=0(j, k=O$ or $W)$. 
From Figure 3, the points $v_{i}=v_{b i}(i=1,2)$ are derived from $u_{1}^{j}\left(v_{1}\right)=0$ and $u_{2}^{k}\left(v_{2}\right)=0$. Consumers whose pre-valuations are not less than $v_{b i}$ will consider to buy from Seller $i(i=1,2)$. In the same way as in Section 3.3, we have $v_{b i}=p_{i}$ when the seller abandons the return policy, and $v_{b i}=\alpha_{i} p_{i}-\delta_{i}+2 \sqrt{\delta_{i} p_{i}\left(1-\alpha_{i}\right)}$ when the seller adopts the return policy.

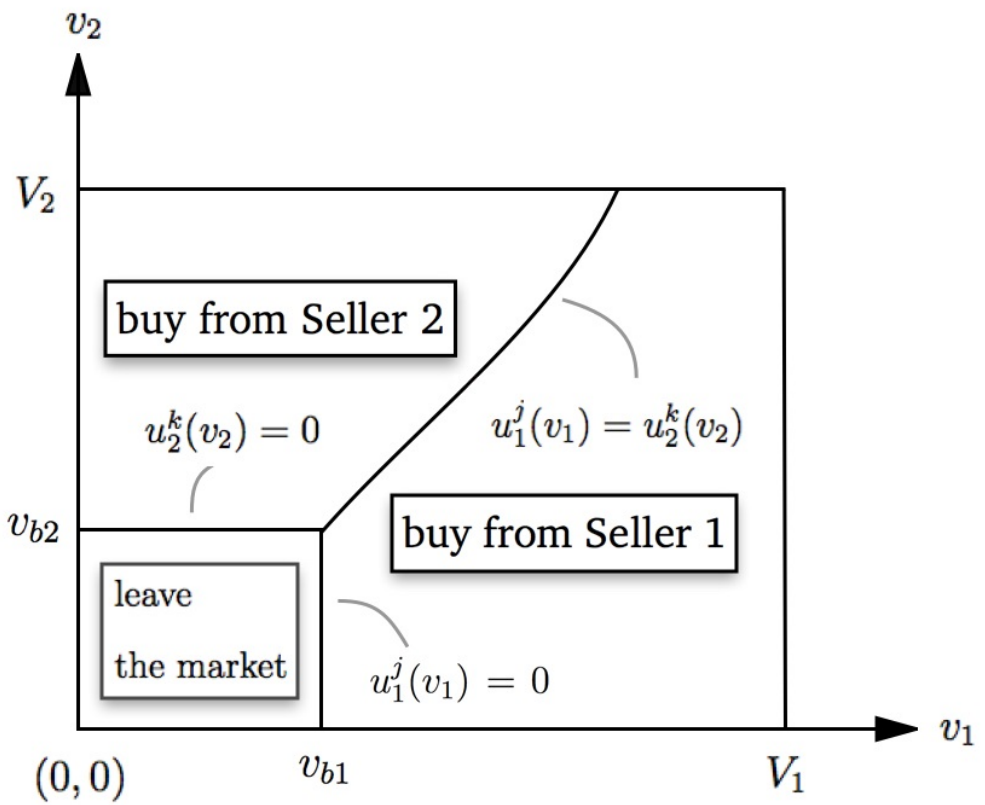

Figure 3. Market division in a duopoly market with return policy.

The boundary $u_{1}^{j}\left(v_{1}\right)=u_{2}^{k}\left(v_{2}\right)$ is re-written as $v_{2}=\left(u_{2}^{k}\right)^{-1}\left(u_{1}^{j}\left(v_{1}\right)\right)$ and $v_{1}=$ $\left(u_{1}^{j}\right)^{-1}\left(u_{2}^{k}\left(v_{2}\right)\right)(j, k=O$ or $W)$. From Figure 3 , the demands for the two sellers are

$$
\begin{aligned}
& D_{d 1}=\int_{v_{b 1}}^{V_{1}} \int_{0}^{\min \left\{\left(u_{2}^{k}\right)^{-1}\left(u_{1}^{j}\left(v_{1}\right)\right), V_{2}\right\}} f\left(v_{1}, v_{2}\right) d v_{2} d v_{1}, \\
& D_{d 2}=\int_{v_{b 2}}^{V_{2}} \int_{0}^{\min \left\{\left(u_{1}^{j}\right)^{-1}\left(u_{2}^{k}\left(v_{2}\right)\right), V_{1}\right\}} f\left(v_{1}, v_{2}\right) d v_{1} d v_{2} .
\end{aligned}
$$

When a seller does not accept returned products, his expected revenue is

$$
\Pi_{i}^{O}=p_{i} D_{d i} .
$$

When the seller adopts a return policy, every consumer who purchases with valuation $v_{i}^{\prime}<v_{r i}$ has probability $\frac{v_{r i}-v_{i}^{\prime}}{2 \delta_{i}}\left(v_{r i}=\alpha_{i} p_{i}+\delta_{i}\right)$ to return the product. The return probability is derived in the same way as in Section 3.3. The expected numbers of consumers who return the products are respectively

$$
\begin{aligned}
& R_{d 1}=\int_{v_{b 1}}^{\min \left(v_{r 1}, V_{1}\right)} \int_{0}^{\min \left\{\left(u_{2}^{k}\right)^{-1}\left(u_{1}^{j}\left(v_{1}\right)\right), V_{2}\right\}} \frac{v_{r 1}-v_{1}}{2 \delta_{1}} f\left(v_{1}, v_{2}\right) d v_{2} d v_{1}, \\
& R_{d 2}=\int_{v_{b 2}}^{\min \left(v_{r 2}, V_{2}\right)} \int_{0}^{\min \left\{\left(u_{1}^{j}\right)^{-1}\left(u_{2}^{k}\left(v_{2}\right)\right), V_{1}\right\}} \frac{v_{r 2}-v_{2}}{2 \delta_{2}} f\left(v_{1}, v_{2}\right) d v_{1} d v_{2} .
\end{aligned}
$$

The revenues of the two sellers consist of the gain from selling and the refund due to returns:

$$
\Pi_{d 1}^{W}=p_{1} D_{d 1}-\left(\alpha_{1} p_{1}\right) R_{d 1}
$$




$$
\Pi_{d 1}^{W}=p_{2} D_{d 2}-\left(\alpha_{2} p_{2}\right) R_{d 2} .
$$

To find the Nash Equilibrium of this game, we first assume that Seller 2 holds strategy of a price $p_{2}$ and return policy $j(j=O$ or $W)$, and try to find out whether Seller 1 will adopt a return policy or not. We add a new notation $c_{1}=\left(1-\alpha_{1}\right) p_{1}$, which represents the return penalty (money not returned) to the consumer if he returns. By substituting $\left(1-\alpha_{1}\right) p_{1}$ with $c_{1}, \Pi_{d 1}^{W}$ can be re-written as $\Pi_{d 1}^{O}$ plus a function of $c_{1}$ (See the proof in the Appendix A):

$$
\begin{aligned}
\Pi_{d 1}^{W}= & \Pi_{d 1}^{O}+R_{d 1}\left(c_{1}\right), \\
\Pi_{d 1}^{O}= & p_{1} D_{d 1}^{W}=p_{1} \int_{p_{1}}^{V_{1}} \min \left\{\left(u_{2}^{k}\right)^{-1}\left(v_{1}-p_{1}\right), V_{2}\right\} \frac{1}{V_{1} V_{2}} d v_{1} \\
R\left(c_{1}\right)= & c_{1}\left(\int_{\sqrt{2 \delta_{1} c_{1}}}^{2 \delta_{1}} \min \left\{\left(u_{2}^{k}\right)^{-1}\left(\frac{v_{1}^{2}}{4 \delta_{1}}-c_{1}\right), V_{2}\right\} \frac{1}{V_{1} V_{2}} d v_{1}\right) \\
& -c_{1}\left(\int_{0}^{\delta_{1}-c_{1}} \min \left\{\left(u_{2}^{k}\right)^{-1}\left(v_{1}\right), V_{2}\right\} \frac{1}{V_{1} V_{2}} d v_{1}\right) .
\end{aligned}
$$

We prove that $R_{d 1}\left(c_{1}\right)$ is positive, and it can be viewed as the benefit brought by the return policy. Based on the formula of $\Pi_{d i}^{W}$, it is clear that adopting a return policy is always valuable for Seller 1, no matter what strategy Seller 2 holds. In the same way, Seller 2 always prefers adopting return policy. So the game comes to an equilibrium, as in Table 3.

Table 3. The equilibrium in a duopoly market.

\begin{tabular}{lll}
\hline Seller 2\Seller 1 & Without & With \\
\hline $\begin{array}{l}\text { without } \\
\text { with }\end{array}$ & $\left(\Pi_{d 1}^{O O}, \Pi_{d 2}^{O O}\right)$ & $\left(\Pi_{d 1}^{W O}, \Pi_{d 2}^{W O}\right)$ \\
& $\left(\Pi_{d 1}^{O W}, \underline{\Pi_{d 2}^{O W}}\right)$ & $\underbrace{\left(\Pi_{d 1}^{W W}, \Pi_{d 2}^{W W}\right)}_{\text {Nash Equilibrium }}$ \\
\hline
\end{tabular}

Our next aim is to find the optimal prices and refunds when both sellers adopt a return policy. By calculations of given $p_{1}, c_{1}$ to find the optimal $p_{2}, c_{2}$ and the same in reverse, the prices in Nash Equilibrium $p_{d i}^{W}$ are the solutions to the following equation set. The equation set for $c_{d i}^{W}, i=1,2$ is too complex so we put them in the Appendix A. The proof for equation set (18) is given in the Appendix A.

$$
\left\{\begin{array}{l}
\left(V_{1}-2 p_{1}\right) \min \left\{\left(u_{2}^{W}\right)^{-1}\left(V_{1}-p_{1}\right), V_{2}\right\}=\int_{v_{b 2}^{W}}^{\min \left\{\left(u_{2}^{W}\right)^{-1}\left(V_{1}-p_{1}\right), V_{2}\right\}}\left(u_{2}^{W}\left(v_{2}\right)\right) d v_{2} \\
\left(V_{2}-2 p_{2}\right) \min \left\{\left(u_{1}^{W}\right)^{-1}\left(V_{2}-p_{2}\right), V_{1}\right\}=\int_{v_{b 1}^{W}}^{\min \left\{\left(u_{1}^{W}\right)^{-1}\left(V_{2}-p_{2}\right), V_{1}\right\}}\left(u_{1}^{W}\left(v_{1}\right)\right) d v_{1}
\end{array}\right.
$$

Using the same way in Figure 2, we find the ranges of the equilibrium prices $p_{d i}^{W}$. We also investigate the ranges of $c_{d i}^{W}$. The results are given in the following proposition.

Proposition 2. In the duopoly model with return policy, both sellers will adopt a return policy. $p_{d i}^{W}$ is larger than $\frac{2 V_{i}}{5}$ and is smaller than $\frac{V_{i}}{2}(i=1,2) . c_{d i}^{W}$ is smaller than $\frac{\delta_{i}}{4}$ and the return proportion to consumers $\alpha_{d i}^{W}$ is smaller than $100 \%(i=1,2)$.

\subsection{Comparison of the Two Duopoly Models}

By comparing the two duopoly models with and without return policy, we can investigate the impact of return policies. We give the price comparison result in Lemma 4. However, the revenues in the two models are too complicated to be compared. Thus, we will make revenue comparison in the numerical study.

Lemma 4. The equilibrium prices of the two sellers with return policy $p_{d i}^{W}(i=1,2)$ are smaller than those without return policy $p_{d i}^{O}(i=1,2)$, respectively. 
Lemma 4 indicates that the prices of the two sellers with return polices are lower than those without return policy. Note that when the sellers can adopt the return policy, both of them will choose the partial refund policy. When the other seller adopts a partial refund policy, the consumers' expected utilities of buying from it can be larger than those without return policy because the product can be returned. Thus, one seller's optimal price when the other seller adopts the return policy is smaller than that when the other seller does not adopt the return policy. Hence, both sellers' optimal prices with return policy are smaller than those without return policy, leading to that the equilibrium prices of the two sellers with return policy are lower than those without return policy.

\section{Analytical Study}

In the above section, we have given the solutions to the monopoly and duopoly models with and without return policy, respectively. We also have compared the two monopoly models and the two duopoly models, to investigate the impact of return policy. In this section, we will make the comparison of the monopoly and the duopoly models with return policy, and the comparison of the monopoly and duopoly models without return policy, to figure out the impact of competition.

\subsection{Comparison of the Monopoly and Duopoly Models}

We start with the comparison of the monopoly and duopoly models without return policy. We consider Seller 1 in the duopoly models as the monopoly seller who faces a competitor Seller 2, so the results of the two models are comparable.

The optimal price of the monopoly seller is $p_{m}^{O}=\frac{V}{2}$. From Lemma 3, the equilibrium price of Seller 1 in the duopoly market $p_{d 1}^{O}$ is larger than $\frac{2 V_{1}}{5}$ and smaller than $\frac{V_{1}}{2}$. $\frac{2 V_{1}}{5}$ is less than the monopoly seller's optimal price $\frac{V_{1}}{2}$ by $20 \%$.

This result shows that the price reduction of the monopoly seller would be less than $20 \%$ when another competitive seller comes into the market. This result is coincident with the numerical study in Section 6.3, which provides a more precise result that the price reduction is smaller than $18 \%$.

The revenue of Seller 1 in the duopoly model is proved to be less than that of the monopoly seller in the monopoly model. This result is quite reasonable because the market is shared by two sellers in the duopoly model.

Proposition 3. One seller in the duopoly model can be considered as the seller in the monopoly model who meets a new competitor. Without return policy, the seller's equilibrium price and revenue in the duopoly model are less than those in the monopoly model, that is, $p_{d 1}^{O}<p_{m}^{O}$ and $\Pi_{d 1}^{O}<\Pi_{m}^{O}$. The percentage of price reduction is less than $20 \%$.

In the comparison of the monopoly and duopoly models with return policy, the results are similar to the results without return policy. The equilibrium price and revenue in the duopoly model are smaller than those in the monopoly model. Additionally, the return penalty cost $c(c=p(1-\alpha))$ is smaller in the duopoly model than that in the monopoly model, too. The results are given in the following proposition.

Proposition 4. One seller in the duopoly model is considered as the seller in the monopoly model who meets a new competitor. With return policy, the seller's equilibrium price, revenue and return penalty cost in the duopoly model are less than those in the monopoly model, that is, $p_{d 1}^{W}<p_{m}^{W}$, $\Pi_{d 1}^{W}<\Pi_{m}^{W}$, and $c_{d 1}^{W}<c_{m}^{W}$. The percentage of price reduction is less than $20 \%$.

As the severity of return policy is measured by the refund proportion $\alpha$, we should also study the comparison of $\alpha$ of the monopoly and duopoly models with return policy. However, due to the complexity of the model, the study of refund proportion $\alpha$ is conducted by the following special case. 


\subsection{A Special Case}

In this subsection, we consider a special case: $V_{1}=V_{2}=V$ and $\delta_{1}=\delta_{2}=\delta$, that is, the parameters of the two sellers are the same. Our aim is to see the severity of return policy is higher or lower in a duopoly market than that in a monopoly market. Although it is a special case, the result may be representative for all cases.

We denote the equilibrium decisions in the special case as $p_{d}^{W}$ and $c_{d}^{W}$, and $c_{d}^{W}=$ $p_{d}^{W}\left(1-\alpha_{d}^{W}\right)$. The solutions of $p_{d}^{W}$ and $c_{d}^{W}$ are given by the following two equations $\left(p_{d}^{W}\right.$ and $c_{d}^{W}$ are simplified to $p$ and $\left.c\right)$ :

$$
\begin{gathered}
p=\sqrt{2 V^{2}-\frac{\delta^{2}}{3}-\frac{8 \delta^{\frac{1}{2}} c^{\frac{3}{2}}}{3}+2 \delta c+\frac{c^{2}}{2}}-V, \\
p(\sqrt{\delta}-\sqrt{c})(\sqrt{\delta}-2 \sqrt{c})-\frac{\delta^{2}}{3}+3 c^{\frac{1}{2}} \delta^{\frac{3}{2}}-5 \delta c+\frac{13 c^{\frac{3}{2}} \delta^{\frac{1}{2}}}{3}-2 c^{2}-\delta c \ln \frac{\delta}{c}=0 .
\end{gathered}
$$

We have obtained that in the monopoly model without return policy, the solutions of price and return penalty are

$$
p_{m}^{W}=\frac{V}{2}, c_{m}^{W}=\frac{\delta}{4}
$$

We prove in the Appendix A that

$$
p_{d}^{W} / c_{d}^{W}<p_{m}^{W} / c_{m}^{W}
$$

Hence,

$$
\alpha_{d}^{W}<\alpha_{m}^{W}
$$

This result shows that the return policy is severer (refund proportion is larger) in the duopoly (competitive) market than that in the monopoly market, which is coincident with the numerical study in Section 6.4. Till now, we have gained some results analytically. However, the results are not complete. We supplement some results in the numerical study.

\section{Numerical Study}

\subsection{Sensitivity Analysis}

To improve the understanding of the impact of the parameters in our models, we conduct a sensitivity analysis. As the two monopoly models have been clearly discussed in Sections 3.2 and 3.3, the analysis in this section only involves the two duopoly models with and without return policy.

We begin with the duopoly model without return policy. There are two parameters: the maximum pre-purchase valuations that the consumers give to the two products $V_{1}, V_{2}$, which affect the decision variables $p_{1}, p_{2}$ and the expected revenues of the two sellers $\Pi_{d 1}^{O}, \Pi_{d 2}^{O}$. We make the sensitivity analysis for Seller 1 of $V_{1}$ and $V_{2}$ by increasing them from 10 to 200 with step size 10. The sensitivity analysis for Seller 2 of $V_{1}$ and $V_{2}$ is the same as that of Seller 1.

Figure 4 illustrates that when $V_{2}$ remains unchanged, as $V_{1}$ increases, both the price and revenue of Seller 1 increase; when $V_{1}$ remains unchanged, as $V_{2}$ increases, the price of Seller 1 first decreases and then increases slightly, and the revenue of Seller 1 decreases slightly. This analysis indicates that, in a competitive market without return policy, as the maximum valuation of the seller's product increases, its revenue increases significantly, and its competitor's price and revenue are slightly influenced.

Next, in the duopoly model with return policy, two parameters are added: $\delta_{1}, \delta_{2}$. Since the valuation uncertainties $\epsilon_{1}$ and $\epsilon_{2}$ are defined as $\epsilon_{1} \sim U\left[-\delta_{1}, \delta_{1}\right]$ and $\epsilon_{2} \sim U\left[-\delta_{2}, \delta_{2}\right]$, these two parameters represent the degree of valuation uncertainties. The two sellers' decision variables are the prices of the two products $p_{1}, p_{2}$, and refund proportions $\alpha_{1}, \alpha_{2}$ if the products are allowed to be returned. 


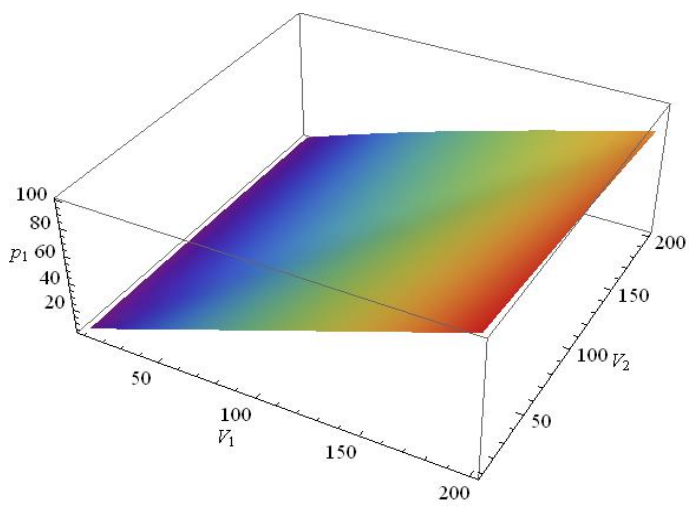

(Price)

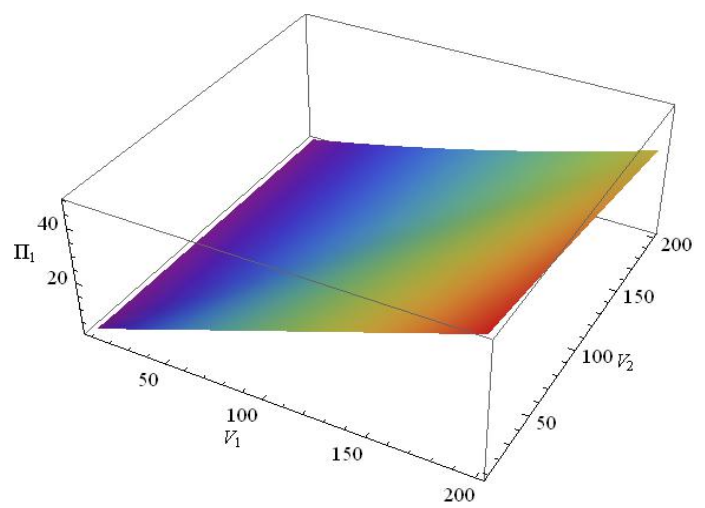

(Revenue)

Figure 4. Sensitivity analysis for Seller 1 of $V_{1}$ and $V_{2}$ without return policy.

We first conduct the sensitivity analysis on the price, refund proportion, and profit of Seller 1 of the parameters $V_{1}, V_{2}$ by increasing them from 50 to 200 with step size 10 . Note that we set $\delta_{1}=\delta_{2}=25$ and we have $V_{i} \geq 2 \delta_{i}, i=1,2$, so $V_{i}$ must be no less than 50 . The sensitivity analysis for Seller 2 of $V_{1}$ and $V_{2}$ is the same as that of Seller 1 .

Figure 5 shows that when $V_{2}$ remains unchanged, as $V_{1}$ increases, the price, refund proportion and revenue of Seller 1 increase; when $V_{1}$ remains unchanged, as $V_{2}$ increases, the price and the refund proportion of Seller 1 first decrease and then increase slightly, and the revenue of Seller 1 decreases. This analysis indicates that, in a competitive market with return policy, as the maximum pre-purchase valuation of a product increases, both the revenue and the refund proportion increase significantly, but the impact on its competitor is mild.
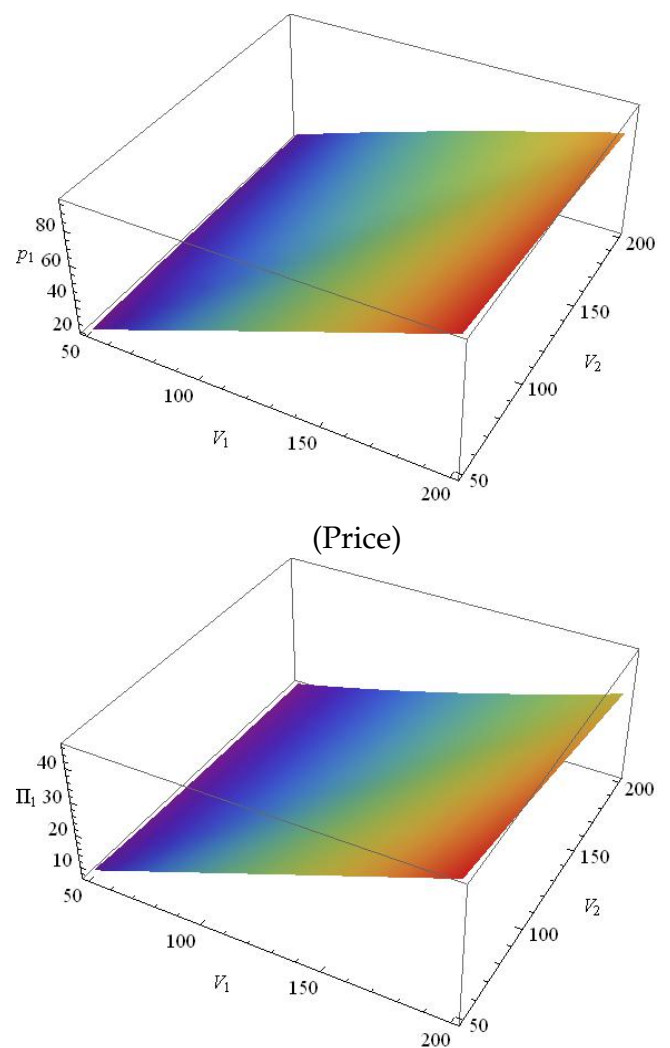

(Revenue)

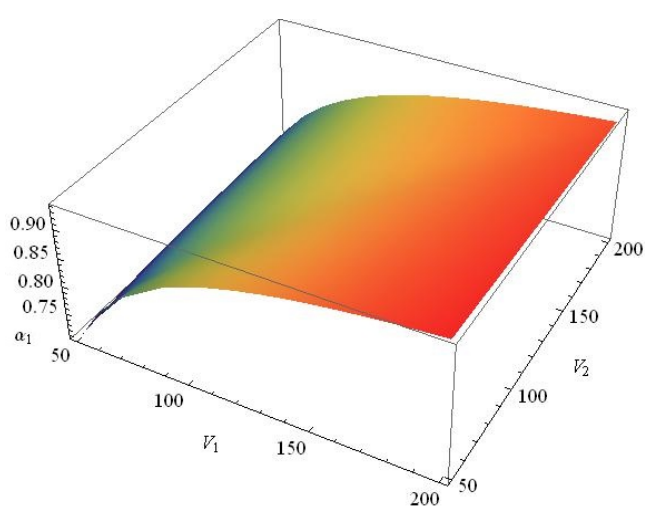

(Refund proportion)

Figure 5. Sensitivity analysis for Seller 1 of $V_{1}$ and $V_{2}$ with return policy. 
Figure 6 presents the sensitivity analysis for Seller 1 of $\delta_{1}$ and $\delta_{2}$ by increasing them from 5 to 50 with step size 5 , and we set $V_{1}=V_{2}=100$. When $\delta_{2}$ remains unchanged, as $\delta_{1}$ increases, the price of Seller 1 decreases slightly and the refund proportion decreases, but the revenue increases; when $\delta_{1}$ remains unchanged, as $\delta_{2}$ increases, the price and revenue decrease, and the refund proportion is unaffected. This analysis suggests that, in a competitive market with return policy, as the uncertainty of one seller's consumer valuation after purchasing increases, its refund proportion decreases and the revenue increases, and its competitor's price and revenue decrease.

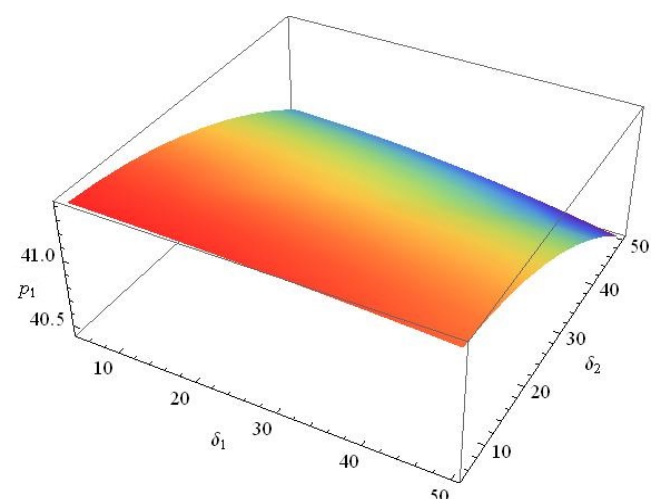

(Price)

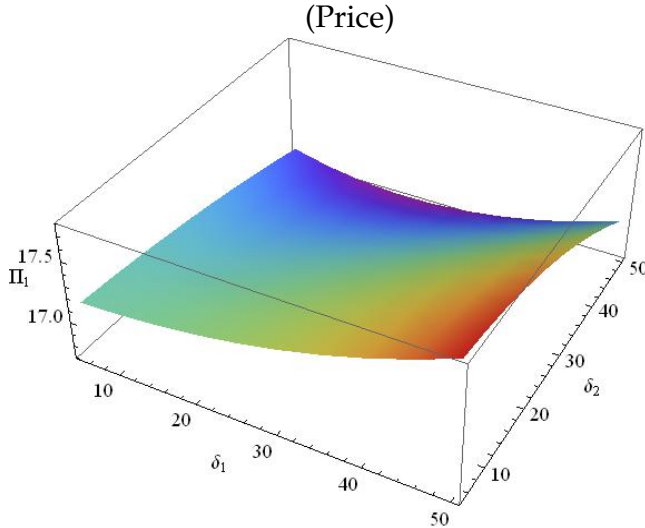

(Revenue)

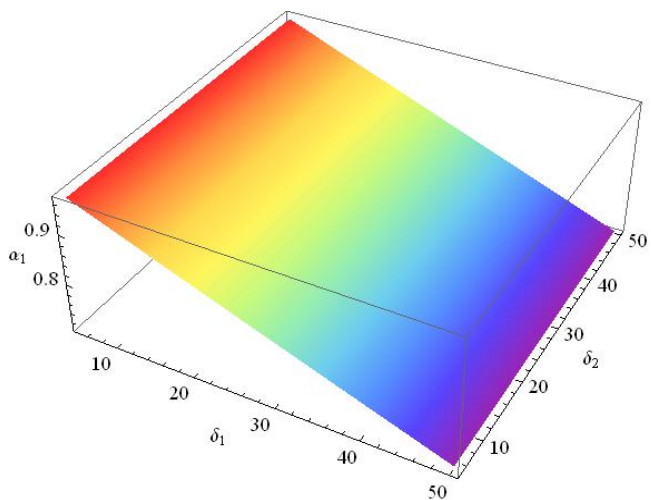

(Refund proportion)

Figure 6. Sensitivity analysis for Seller 1 of $\delta_{1}$ and $\delta_{2}$ with return policy.

\subsection{Comparison of the Two Duopoly Models}

In this subsection, we show the impact of return policy in a competitive market by comparing the two duopoly models with and without return policy. We compare the equilibrium prices and corresponding revenues of Seller 1 by the difference between the two models, that is, $\Delta p_{d 1}=p_{d 1}^{W}-p_{d 1}^{O}$ and $\Delta \Pi_{d 1}=\Pi_{d 1}^{W}-\Pi_{d 1}^{O}$, as $V_{1}$ and $V_{2}$ increase from 50 to 200 with step size 10 and $\delta_{1}=25, \delta_{2}=25$. The comparison of Seller 2 is the same as that of Seller 1.

From Figure 7, we find that the price difference is negative, which indicates that the equilibrium price of Seller 1 with return policy is lower than that without return policy in a duopoly market. The revenue difference is sometimes positive and sometimes negative, which means that the revenue of Seller 1 with return policy may be higher or lower than that without return policy. When $V_{1}$ is small enough, the revenue of Seller 1 with return policy can be larger than that without return policy. 


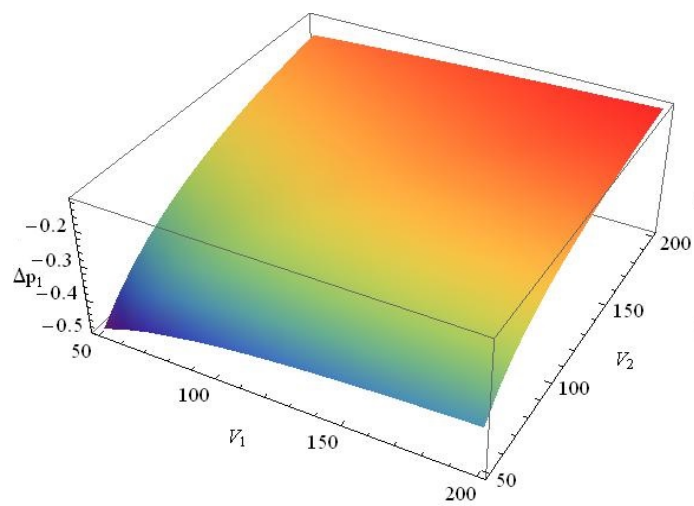

(Price)

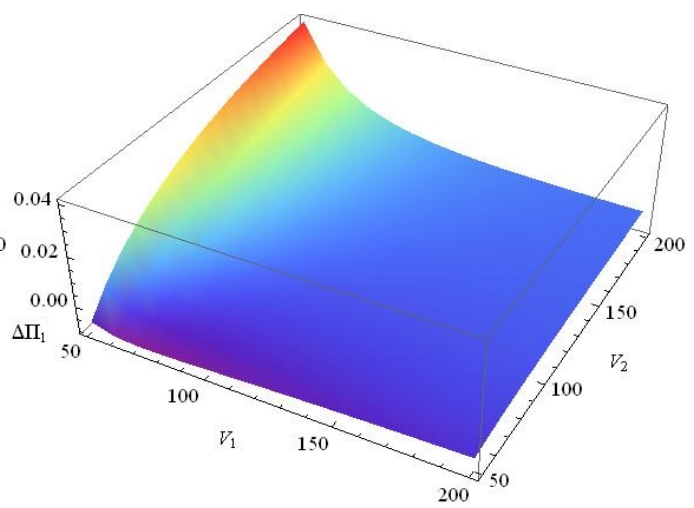

(Revenue)

Figure 7. The changes of Seller 1 from without return policy to with return policy.

\subsection{Comparison of the Monopoly and Duopoly Models without Return Policy}

In this subsection, we numerically compare the monopoly and duopoly models without return policy. When return policy is not adopted, the only decision variable of the seller is the price. We consider the duopoly model as the monopoly seller in a monopoly model meets a new competitor in the market. By comparing the optimal price of the monopoly seller in the monopoly market and the equilibrium price in the duopoly market, we can investigate the price reduction of the seller when a new competitor shows up in the market in our consumer-valuation-based model.

From Figure 8, when one monopoly seller with $V_{1}$ meets a new seller with $V_{2}$ ( $V_{1}$ and $V_{2}$ are set from 10 to 200 with step size 10) in the market, the monopoly seller reduces its price, and the reduction rate is less than $18 \%$, which is consistent with our analytical result (the price reduction is less than $20 \%$ ). The largest reduction is about $17.1572 \%$ when $V_{1}=V_{2}$. The change of revenue is negative, so the monopoly seller's revenue is also reduced. When $V_{2}$ remains unchanged, as $V_{1}$ increases, the revenue reduction of the monopoly seller increases; when $V_{1}$ remains unchanged, as $V_{2}$ increases, the revenue reduction decreases.

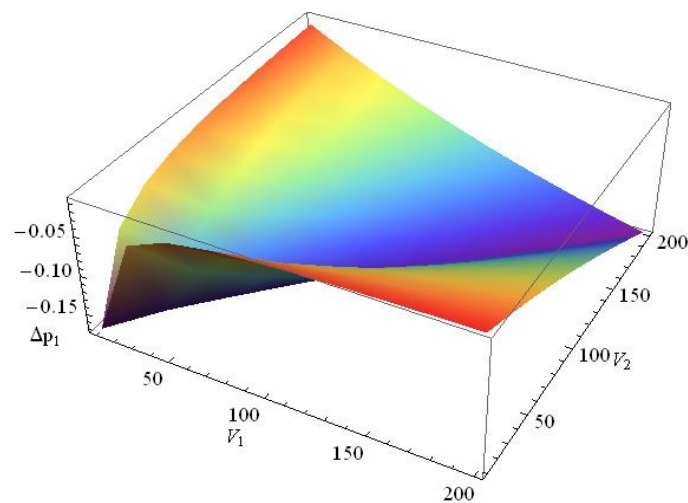

(Price)

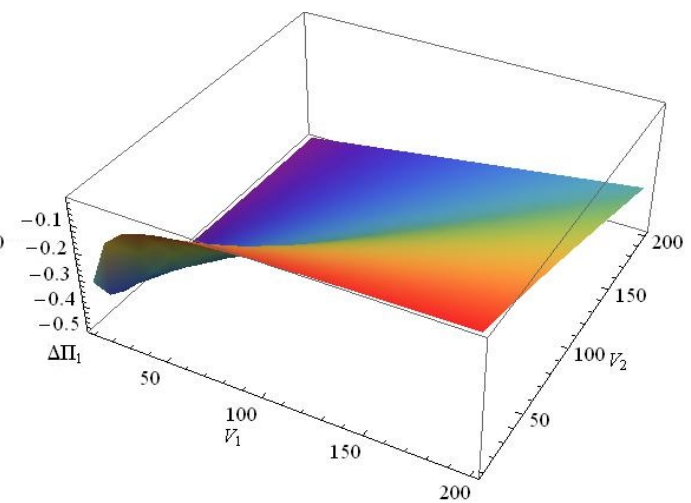

(Revenue)

Figure 8. The changes of the monopoly seller facing a new seller in the market without return policy.

\subsection{Comparison of the Monopoly and Duopoly Models with Return Policy}

According to the Sections 3.4 and 4.2, return policy is always chosen by a seller, no matter the market is monopoly or duopoly. In the special case, we obtain that the refund proportion is smaller in the duopoly model, which means that the return policy is severer in a competitive market than that in a monopoly market. Now, we study the general case numerically.

In Figure 9, one seller with $V_{1}$ changing from 50 to 200 with step size 10 and $\delta_{1}=25$ meets a new market participant with $V_{2}$ changing from 50 to 200 with step size 10 and 
$\delta_{2}=25$. The seller who is first in the market reduces the price by less than $18 \%$. The difference of refund proportion before and after facing the competitor is negative, which indicates that the seller also reduces its refund proportion, that is, the seller provides a severer return policy to the consumers in a competitive market. The reason for this counter-intuitive result may be that the benefit of the un-refunded proportion extracted from consumer return overweighs the negative influence on the consumers' purchasing decisions due to the return policy with a lower refund.

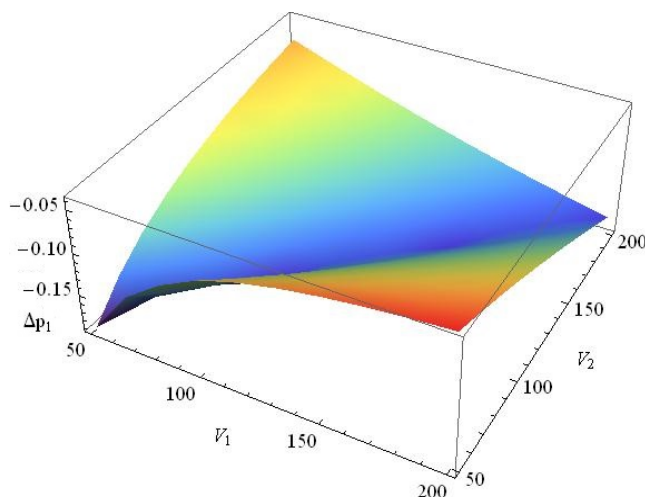

(Price)

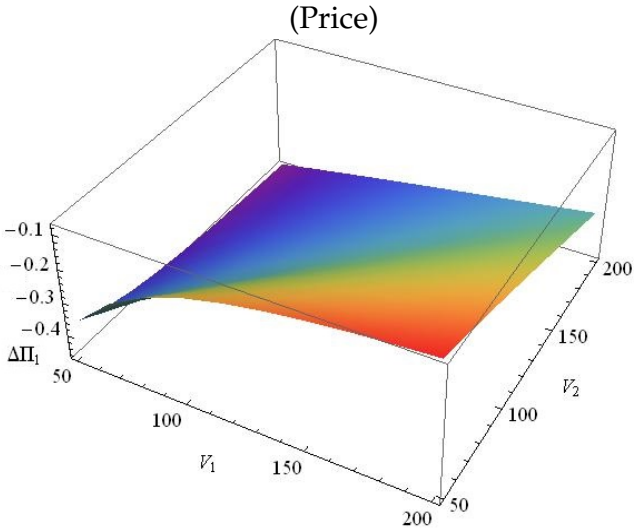

(Revenue)

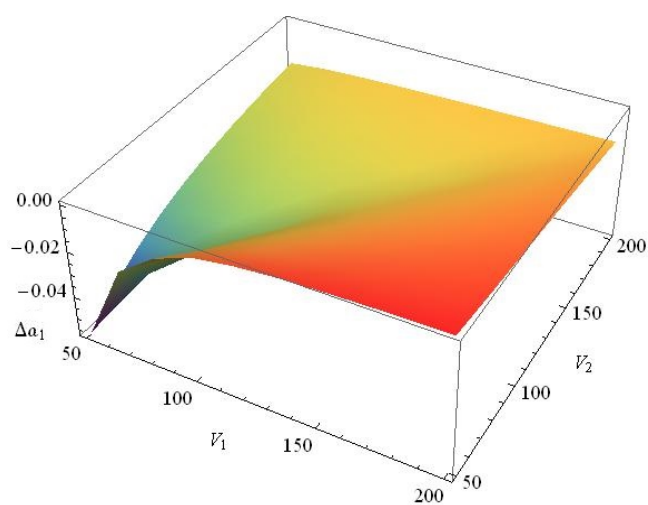

(Refund proportion)

Figure 9. The changes of the monopoly seller facing a new competitor in the market with return policy.

\section{Discussions}

In this section, we would like to make some discussions about our model design and the managerial implications of our research findings. First, we would like to show the practical meaning of the consumer-valuation-based analysis in a more precisely way. Second, we will show the managerial implications of our result of pricing policy and its comparison with the traditional price competition models. Third, we will show the accordance of our results of return policy with those in literature and the difference between them.

\subsection{Consumer-Valuation-Based Analysis}

Consumers' valuations in online purchasing are influenced by many aspects. Ref. [32] have conducted a thorough survey about consumers' perception in online shopping. The results of the survey can show that one consumer will have different preferences/valuations on different online products and the choices of different consumers also differ. Moreover, Ref. [3] show that consumers are more willing to spend time in-store, repurchasing or revisiting in an online store because of suitable music and colors. Refs. [33,34] find that consumers' purchasing behaviors are significantly affected by efficient digital signage-based online layout. Additionally, the results of [35] indicate that the sellers can enhance the consumers' purchasing experience by providing alternative e-channel touchpoints. Ref. [4] develop an information system-consumer behavior model and conduct an online survey for e-commerce to analyze the factors that impact online shopping experience. 
Thus, consumer-valuation-based analysis has realistic basis. Our research considers one consumer's valuation differentiation on different products and the consumers' valuation differentiation on one product, which is unique. It is worth investigating that how the sellers make decisions on the pricing and return policies in our consumer-valuationbased setting.

\subsection{Pricing Policy}

The main result of our research about pricing policy is that the equilibrium price in competition is higher than $80 \%$ of the price in the monopoly market. This result is obtained in the consumer-valuation-based setting.

Two traditional price competition models are the Cournot and Bertrand competition. In the Cournot competition, the market price is determined by the total quantity supplied by the firms. In the Bertrand competition, the sellers will provide the lowest price which can serve the whole market.

Our research also builds a price competition model, but ours is based on the consumer valuations in e-commerce market. The result of our price competition model provides the managerial implication for the e-commerce sellers that the price deduction from a monopoly market to a competitive market can be not too large.

\subsection{Return Policy}

Our research finds that the return policy in the competitive market can be severer than that in the monopoly market. This result is in accord with the result of [2] that the partial refund can be sustained in a competitive market and the return policy can be severer than that in the monopoly market. However, the difference between our researches is that [2] develop a Salop circle and find that the severer return policy can be adopted only when consumers are uncertain about preferences between products. Our research shows that in the consumer-valuation-based analysis, a severer return policy can always be adopted in the competitive market than that in the monopoly market.

The reason of the severer return policy in competition is that the lower refund to consumers can keep the consumers from returning the product and buy from the competitor, which will be beneficial to the seller. However, in a monopoly market, the consumers will buy again from the seller when they return products. The seller can benefit from selling no matter the consumers return products or not. Thus, the seller in the monopoly market will provide a lenient return policy to the consumers to increase the consumers' expected purchasing utility and consequently increase the demand of the product and the seller's profit. Consequently, the return policy in competition can be severer than that in the monopoly market.

This result gives contribution to environmental protection. A severer return policy in the competitive market can prevent a part of consumers from returning products, especially to those opportunistic consumers.

\section{Conclusions}

This research is the first to study the pricing and return policy using two-dimensional valuation-based models. We consider one consumer's independent valuations on two products and the differentiation of all consumers' valuation on each product. To answer the three research questions, four models are developed: the monopoly models with and without return policy, and the duopoly models with and without return policy. The monopoly models are formulated as nonlinear optimization programs, while the duopoly models are investigated using game theory. The return policy is characterized by the refund proportion to the consumer if a product is returned.

We provide the optimal or Nash Equilibrium solutions for the four models and conduct some analytical and numerical studies. The results about the seller's decision on return policy are as follows: In a monopoly market, the seller will adopt return policy. In a duopoly market, both sellers adopt the return policy in the Nash Equilibrium. 
The impact of return policy is captured by comparing the models with and without return policy. We find that in a monopoly market, return policy benefits the seller. However, in a duopoly market, return policy may not bring more revenues to the two sellers.

The impact of competition is shown in the comparison of the monopoly and duopoly models: In the duopoly market, one seller is considered as the monopoly seller facing a new competitor in the market. The seller's price and revenue in the duopoly market are both lower than those in the monopoly market. The equilibrium price in the duopoly models cannot be below than $80 \%$ of the optimal price in the monopoly model, which indicates that a monopoly seller will reduce its price by no more than $20 \%$ when there comes a competitor. One more interesting result is that the severity of the seller's return policy is higher in a duopoly (competitive) market than that in a monopoly market.

This study provides management insights about how a monopoly seller should react to a new competitor in the market, and the return policy decisions of the sellers in a competitive market. Except for managerial insights, the results of this study also have practical meaning in environmental protection. We provide implications in return policy decisions in e-commerce, which will help the sellers manage consumer returns, and consequently, reduce harm to environment.

We list the limitations of this study and some future research directions. First, we assume that the consumers' valuations on the two products are uniformly distributed and the consumers' valuations on two products are independent. In the future work, more general assumptions on the consumers' valuations should be considered. Second, our research only focuses on the pricing and return policy. More studies are expected concerning the quantity and quality decisions of the sellers. Third, our research considers the return policy, however, exchange policy can also be offered to consumers by the sellers. Thus, how to the make exchange policy decision can also be investigated and discussed.

Author Contributions: Conceptualization, X.W.; Methodology, C.T.N.; Project administration, H.J. and L.M.; Writing-original draft, X.W.; Writing-review and editing, H.J. and X.W. All authors have read and agreed to the published version of the manuscript.

Funding: This work was supported by the National Natural Science Foundation of China under Grant 71871145, 71471118 and 71904129; the China Postdoctoral Science Foundation under Grant 2018M643186 and 2019M663082.

Institutional Review Board Statement: Not applicable.

Informed Consent Statement: Not applicable.

Data Availability Statement: Not applicable.

Conflicts of Interest: The authors declare no conflicts of interest.

\section{Appendix A}

Proof for Lemma 2 in Section 3.3. We consider two cases because there is $\min \left\{v_{r}, V\right\}$ in Equation (3):

(1) when $v_{r}=\alpha p+\delta \geq V$ :

$$
\Pi_{m}^{W}=p \frac{V-v_{b}}{V}-\alpha p \int_{v_{b}}^{V} \frac{\alpha p+\delta-v}{2 \delta V} d v=\frac{1}{4 \delta V}\left(V-v_{b}\right)\left[4 \delta p+\alpha p\left(V+v_{b}\right)-2 \alpha p(\alpha p+\delta)\right],
$$

where $v_{b}=\alpha p-\delta+2 \sqrt{\delta(p-\alpha p)}$. Let $\alpha p=t$, and $p=t+\frac{\left(v_{b}-t+\delta\right)^{2}}{4 \delta}$, then $\Pi_{m}^{W}$ is a function of $t$ and $v_{b}$, and $t \geq V-\delta$.

$$
\frac{\partial \Pi_{m}^{W}}{\partial(t)}=\frac{V-v_{b}}{4 \delta V}\left(V-v_{b}-2 t\right) \leq \frac{V-v_{b}}{4 \delta V}\left[V-v_{b}-2(V-\delta)\right]=\frac{V-v_{b}}{4 \delta V}\left(-V+2 \delta-v_{b}\right) .
$$

With $\delta<\frac{V}{2}, \frac{\partial \Pi_{m}^{W}}{\partial(t)}<0$, so the optimal solution in case (1) is at the smallest $\alpha p=V-\delta$, that is, $\alpha p+\delta=v_{r}=V$.

(2) when $v_{r}=\alpha p+\delta \leq V$ :

$\Pi_{m}^{W}=p \frac{V-v_{b}}{V}-\alpha p \int_{v_{b}}^{v_{r}} \frac{\alpha p+\delta-v}{2 \delta V} d v=\frac{1}{V}\left[p(V-p)+[\sqrt{c}(\sqrt{\delta}-\sqrt{c})]^{2}\right]=\Pi_{m}^{O}+R_{m}(c)$.

The optimal solution is $p^{*}=\frac{V}{2}$ and $\sqrt{c}=\frac{\sqrt{\delta}}{2}$, so $\alpha^{*}=1-\frac{\delta}{2 V}$. 
The optimal solution in case (1) is included in case (2), so the optimal solution is $p^{*}=\frac{V}{2}$ and $\alpha^{*}=1-\frac{\delta}{2 V}$ in case (2).

Proof for Equations (7) and (18) in Sections 4.1 and 4.2. The equilibrium prices in the duopoly models with and without return policy are given in Equation Sets (7) and (18). We first give the calculations for obtaining them.

$\Pi_{d 1}^{k}=p_{1} \frac{1}{V_{1} V_{2}} \int_{p_{1}}^{V_{1}} \min \left\{\left(u_{2}^{k}\right)^{-1}\left(v_{1}-p_{1}\right), V_{2}\right\} d v_{1}, k=O, W$. We consider two cases:

(1) when $\left(u_{2}^{k}\right)^{-1}\left(V_{1}-p_{1}\right)<V_{2}: \Pi_{d 1}^{k}=p_{1} \frac{1}{V_{1} V_{2}} \int_{p_{1}}^{V_{1}}\left(u_{2}^{k}\right)^{-1}\left(v_{1}-p_{1}\right) d v_{1}$

$=p_{1} \int_{p_{1}}^{V_{1}} x d\left(u_{2}^{k}+p_{1}\right)=p_{1}\left[\left(V_{1}-p_{1}\right)\left(u_{2}^{k}\right)^{-1}\left(V_{1}-p_{1}\right)-\int_{\left(u_{2}^{k}\right)^{-1}(0)}^{\left(u^{k}\right)^{-1}\left(V_{1}-p_{1}\right)} u_{2}^{k}(x) d x\right]$.

(2) when $\left(u_{2}^{k}\right)^{-1}\left(V_{1}-p_{1}\right) \geq V_{2}: \Pi_{d 1}^{k}=p_{1} \int_{p_{1}}^{u_{2}^{k}\left(V_{2}\right)+p_{1}}\left(u_{2}^{k}\right)^{-1}\left(v_{1}-p_{1}\right) d v_{1}$ $+p_{1} \int_{u_{2}^{k}\left(V_{2}\right)+p_{1}}^{V_{1}}\left(V_{2}\right) d v_{1}$.

For the two cases, we have

$\frac{\partial \Pi_{d 1}^{k}}{\partial p_{1}}=\left(V_{1}-2 p_{1}\right) \min \left\{\left(u_{2}^{k}\right)^{-1}\left(V_{1}-p_{1}\right), V_{2}\right\}-\int_{\left(u_{2}^{k}\right)^{-1}(0)}^{\min \left\{\left(u_{2}^{k}\right)^{-1}\left(V_{1}-p_{1}\right), V_{2}\right\}}\left(u_{2}^{k}\left(v_{2}\right)\right) d v_{2}$.

And $\frac{\partial^{2} \Pi_{d 1}^{k}}{\partial p_{1}^{2}}=-2 \min \left\{\left(u_{2}^{k}\right)^{-1}\left(V_{1}-p_{1}\right), V_{2}\right\}-p_{1} \frac{\partial \min \left\{\left(u_{2}^{k}\right)^{-1}\left(V_{1}-p_{1}\right), V_{2}\right\}}{\partial p_{1}}<0$.

$\left.\frac{\partial \Pi_{d 1}^{k}}{\partial p_{1}}\right|_{p_{1}=0}>0$ and $\left.\frac{\partial \Pi_{d 1}^{k}}{\partial p_{1}}\right|_{p_{1}=V_{1}}<0$, so the optimal $p_{1}$ is at $\frac{\partial \Pi_{d 1}^{k}}{\partial p_{1}}=0$. It is the same for $p_{2}$.

Proof for $\Pi_{d 1}^{W}=\Pi_{d 1}^{O}+\boldsymbol{R}_{d 1}\left(c_{1}\right)$ in Section 4.2. We first prove that $p_{i} \leq v_{r i}<V_{i}$. Three cases are considered:

(1) $v_{r i}<p_{i}\left(<V_{i}\right)$ : all consumers' valuation will be high enough to not return the product, that is, the revenue will be the same as the revenue without return policy. $\Pi_{d i}^{W}=\Pi_{d 1}^{O}$.

(2) $p_{i} \leq v_{r i}<V_{i}$ : consumers with valuation lower than $v_{r i}$ have the probability to return and consumers with valuation higher than $v_{r i}$ will keep the product. $\Pi_{d i}^{W}=\Pi_{d i}^{O}+R_{d i}\left(c_{i}\right)$.

(3) $\left(p_{i}<\right) V_{i} \leq v_{r i}$ : all consumers have the probability to return the product. $\Pi_{d i}^{W}=$ $\Pi_{d i}^{O}+R_{d i}^{\prime}\left(c_{i}\right) \cdot R_{d i}^{\prime}\left(c_{i}\right)=R_{d i}\left(c_{i}\right)-c_{i} \int_{V_{i}}^{v_{r i}}\left(\frac{\left(v_{i}+\delta_{i}+c_{i}-p_{i}\right)^{2}}{4 \delta_{i}}-c_{i}\right) d v_{i}$.

It is clear that the optimal choice happens in the second case.

$\Pi_{d 1}^{W}=p_{1} D_{d 1}-\left(\alpha_{1} p_{1}\right) R_{d 1}$

$=p_{1} \int_{v_{b}}^{V_{1}} \int_{0}^{\min \left\{\left(u_{2}^{k}\right)^{-1}\left(u_{1}^{W}\left(v_{1}\right)\right), V_{2}\right\}} \frac{1}{V_{1} V_{2}} d v_{2} d v_{1}$

$-\left(\alpha_{1} p_{1}\right) \int_{v_{b 1}}^{\alpha_{1} p_{1}+\delta_{1}} \int_{0}^{\min \left\{\left(u_{2}^{k}\right)^{-1}\left(u_{1}^{W}\left(v_{1}\right)\right), V_{2}\right\}} \frac{v_{r 1}-v_{1}}{2 \delta_{1}} \frac{1}{V_{1} V_{2}} d v_{2} d v_{1}$

$=p_{1} \int_{p_{1}}^{V_{1}} \min \left\{\left(u_{2}^{k}\right)^{-1}\left(v_{1}-p_{1}\right), V_{2}\right\} \frac{1}{V_{1} V_{2}} d v_{1}$

$-p_{1} \int_{p_{1}}^{\alpha_{1} p_{1}+\delta_{1}} \min \left\{\left(u_{2}^{k}\right)^{-1}\left(v_{1}-p_{1}\right), V_{2}\right\} \frac{1}{V_{1} V_{2}} d v_{1}$

$+p_{1} \int_{v_{b 1}}^{\alpha_{1} p_{1}+\delta_{1}} \min \left\{\left(u_{2}^{k}\right)^{-1}\left(\left(\frac{\left(v_{1}+\delta_{1}-\alpha_{1} p_{1}\right)^{2}}{4 \delta_{1}}+\alpha_{1} p_{1}-p_{1}\right), V_{2}\right\} \frac{1}{V_{1} V_{2}} d v_{1}\right.$

$-\left(\alpha_{1} p_{1}\right) \int_{v_{b 1}}^{\alpha_{1} p_{1}+\delta_{1}} \min \left\{\left(u_{2}^{k}\right)^{-1}\left(\frac{\left(v_{1}+\delta_{1}-\alpha_{1} p_{1}\right)^{2}}{4 \delta_{1}}+\alpha_{1} p_{1}-p_{1}\right), V_{2}\right\} \frac{1}{V_{1} V_{2}} d v_{1}$

$+\left(\alpha_{1} p_{1}\right) \int_{p_{1}}^{\alpha_{1} p_{1}+\delta_{1}} \min \left\{\left(u_{2}^{k}\right)^{-1}\left(v_{1}-p_{1}\right), V_{2}\right\} \frac{1}{V_{1} V_{2}} d v_{1}$

$=\Pi_{d 1}^{O}+R_{d 1}\left(c_{1}\right)$,

because the first part is $\Pi_{d 1}^{O}$; the second and fifth parts are combined to be second part in $R_{d 1}\left(c_{1}\right)$; the third and fourth parts are combined to be first part in $R_{d 1}\left(c_{1}\right)$.

Proof for Lemma 3 and Proposition 2 in Sections 4.1 and 4.2. For the equation $\left(V_{1}-2 p_{1}\right)$ $\min \left\{\left(u_{2}^{k}\right)^{-1}\left(V_{1}-p_{1}\right), V_{2}\right\}=\int_{\left(u_{2}^{k}\right)^{-1}(0)}^{\min \left\{u_{2}^{k}\left(V_{1}-p_{1}\right), V_{2}\right\}}\left(u_{2}^{k}\left(v_{2}\right)\right) d v_{2}$, we first have $V_{1}-2 p_{1}>0$, so $p_{d 1}^{k}<\frac{V_{1}}{2}, k=O, W$. $\left(u_{2}^{k}\right)^{-1}\left(v_{2}\right)$ are given in Equations (8) and (9). Additionally, $\left(u_{2}^{O}\right)^{-1}\left(v_{2}\right)=v_{2}+p_{2} ;\left(u_{2}^{W}\right)^{-1}\left(v_{2}\right)=\alpha_{2} p_{2}-\delta_{2}+2 \sqrt{\delta_{2}\left(v_{2}+c_{2}\right)}$ when $v_{2} \leq \delta_{2}-c_{2} ;$ $\left(u_{2}^{W}\right)^{-1}\left(v_{2}\right)=v_{2}+p_{2}$ when $v_{2}>\delta_{2}-c_{2}$. We consider two cases:

(1) when $\left(u_{2}^{k}\right)^{-1}\left(v_{1}-p_{1}\right)<V_{2}:\left(V_{1}-2 p_{1}\right)\left(u_{2}^{k}\right)^{-1}\left(V_{1}-p_{1}\right)=\int_{\left(u_{2}^{k}\right)^{-1}(0)}^{\left(u^{k}\right)^{-1}\left(V_{1}-p_{1}\right)}$ $\left(\left(u_{2}^{k}\left(v_{2}\right)\right) d v_{2}\right.$. 
In this case, $-2\left(u_{2}^{k}\right)^{-1}\left(V_{1}-p_{1}\right) \frac{\partial p_{1}}{\partial p_{2}}=\int_{\left(u_{2}^{k}\right)^{-1}(0)}^{\left(u^{k}\right)^{-1}\left(V_{1}-p_{1}\right)} \frac{\partial u_{2}^{k}\left(v_{2}\right)}{\partial p_{2}} d v_{2}+p_{1} \frac{\partial\left(u_{2}^{k}\right)^{-1}\left(V_{1}-p_{1}\right)}{\partial p_{2}}<0$. and $-2\left(u_{2}^{k}\right)^{-1}\left(V_{1}-p_{1}\right) \frac{\partial^{2} p_{1}}{\partial p_{2}^{2}}=\int_{\left(u_{2}^{k}\right)^{-1}(0)}^{\left(u^{k}\right)^{-1}\left(V_{1}-p_{1}\right)} \frac{\partial^{2} u_{2}^{k}\left(v_{2}\right)}{\partial p_{2}^{2}} d v_{2}+\left(V_{1}-p_{1}+3 \frac{\partial p_{1}}{\partial p_{2}}\right)$ $\frac{\partial\left(u_{2}^{k}\right)^{-1}\left(V_{1}-p_{1}\right)}{\partial p_{2}}+p_{1} \frac{\partial^{2}\left(u_{2}^{k}\right)^{-1}\left(V_{1}-p_{1}\right)}{\partial^{2} p_{2}}-\left.\frac{\partial u_{2}^{k}\left(v_{2}\right)}{\partial p_{2}}\right|_{v_{2}=\left(u_{2}^{k}\right)^{-1}(0)} \frac{\partial\left(u_{2}^{k}\right)^{-1}(0)}{\partial p_{2}}>0$.

(2) when $\left(u_{2}^{k}\right)^{-1}\left(v_{1}-p_{1}\right) \geq V_{2}:\left(V_{1}-2 p_{1}\right) V_{2}=\int_{\left(u_{2}^{k}\right)^{-1}(0)}^{V_{2}}\left(u_{2}^{k}\left(v_{2}\right)\right) d v_{2}$.

In this case, $-\frac{V_{2}}{2} \frac{\partial p_{1}}{\partial p_{2}}=\int_{\left(u_{2}^{k}\right)^{-1}(0)}^{V_{2}}\left(\frac{\partial u_{2}^{k}\left(v_{2}\right)}{\partial p_{2}}\right) d v_{2}<0$

and $-\frac{V_{2}}{2} \frac{\partial^{2} p_{1}}{\partial p_{2}^{2}}=\int_{\left(u_{2}^{k}\right)^{-1}(0)}^{V_{2}}\left(\frac{\partial^{2} u_{2}^{k}\left(v_{2}\right)}{\partial p_{2}^{2}}\right) d v_{2}-\left.\frac{\partial u_{2}^{k}\left(v_{2}\right)}{\partial p_{2}}\right|_{v_{2}=\left(u_{2}^{k}\right)^{-1}(0)} \frac{\partial\left(u_{2}^{k}\right)^{-1}(0)}{\partial p_{2}}>0$.

For all $u_{2}^{k}\left(v_{2}\right.$, we have $\frac{\partial p_{1}\left(p_{2}\right)}{\partial p_{2}}>0$ and $\frac{\partial^{2} p_{1}\left(p_{2}\right)}{\partial p_{2}^{2}}<0$. From Figure 2 , we have $p_{d 1}^{k}>\frac{2 V_{1}}{5}$.

Because $\Pi_{d 1}^{W}=\Pi_{d 1}^{O}+R_{d 1}\left(c_{1}\right)$, the sellers will adopt return policy in duopoly market.

As $c_{1}$ increases, $\frac{\partial R_{d 1}\left(c_{1}\right)}{\partial c_{1}}$ is positive and then negative. The optimal $c_{d 1}^{W}$ is at $\frac{\partial R_{d 1}\left(c_{1}\right)}{\partial c_{1}}=0$, which satisfies $v_{b 2}^{W}\left(\sqrt{\delta_{1}}-\sqrt{c_{1}}\right)\left(\sqrt{\delta_{1}}-2 \sqrt{c_{1}}\right)+\int_{v_{b 2}^{W}}^{\min }\left\{\left(u_{2}^{W}\right)^{-1}\left(\delta_{1}-c_{1}\right), V_{2}\right\}\left(u_{2}^{W}\left(v_{2}\right)+\delta_{1}+2 c_{1}-\right.$ $\left.2 \sqrt{\delta_{1}\left(u_{2}^{W}\left(v_{2}\right)+c_{1}\right)}-c_{1} \sqrt{\frac{\delta_{1}}{u_{2}^{W}\left(v_{2}\right)+c_{1}}}\right) d v_{2}=0$

$\left.\frac{\partial R_{d 1}\left(c_{1}\right)}{\partial c_{1}}\right|_{c_{1}=\frac{\delta_{1}}{4}}<0$, so $c_{d 1}^{W}<\frac{\delta_{1}}{4}$. Also, $\left.\frac{\partial R_{d 1}\left(c_{1}\right)}{\partial c_{1}}\right|_{c_{1}=0}>0$, so $c_{d 1}^{W}>0$, and $\alpha_{d i}^{W}<100 \%$.

Proof for Lemma 4 in Section 4.3. The equilibrium prices in the duopoly models with and without return policy are given in Equation Sets (7) and (18). The two sets are in similar form.

Without return policy: $\left(V_{1}-2 p_{1}\right) \min \left\{V_{1}-p_{1}+p_{2}, V_{2}\right\}=\int_{p_{2}}^{\min \left\{V_{1}-p_{1}+p_{2}, V_{2}\right\}}\left(v_{2}-\right.$ $\left.p_{2}\right) d v_{2}$.

With return policy: $\left(V_{1}-2 p_{1}\right) \min \left\{\left(u_{2}^{W}\right)^{-1}\left(V_{1}-p_{1}\right), V_{2}\right\}=\int_{v_{b 2}^{W}}^{\min \left\{\left(u_{2}^{W}\right)^{-1}\left(V_{1}-p_{1}\right), V_{2}\right\}}$ $\left(u_{2}^{W}\left(v_{2}\right)\right) d v_{2}$.

$p_{d 1}^{O}$ and $p_{d 1}^{W}$ are the solutions to the above two equations. We first employ a $\hat{p_{1}}$ who satisfies: $\left.\left(V_{1}-2 p_{1}\right) \min \left\{\left(u_{2}^{W}\right)^{-1}\left(V_{1}-p_{1}\right), V_{2}\right\}=\int_{p_{2}}^{\min \left\{\left(u_{2}^{W}\right)^{-1}\left(V_{1}-p_{1}\right), V_{2}\right\}}\left(v_{2}-p_{2}\right)\right) d v_{2}$.

Since $u_{2}^{W}\left(v_{2}\right)>v_{2}-p_{2}$, it is obvious that $p_{d 1}^{W}<\hat{p_{1}}$.

Let $M$ satisfies $\left(V_{1}-2 p_{1}\right) M=\int_{p_{2}}^{M}\left(v_{2}-p_{2}\right) d v_{2}$, and $M>p_{2}$. $\left.\frac{p_{2}^{2}}{M^{2}}\right)>0$

$\frac{\partial\left(\left(V_{1}-2 p_{1}\right) M\right)}{\partial M}=V_{1}-2 p_{1}=\frac{\partial\left(\int_{p_{2}}^{M}\left(v_{2}-p_{2}\right) d v_{2}\right)}{\partial M}=\frac{M}{2}-p_{2}+\frac{p_{2}^{2}}{2 M}$ and $\frac{\partial\left(V_{1}-2 p_{1}\right)}{\partial M}=\frac{1}{2}(1-$

Since $\min \left\{V_{1}-p_{1}+p_{2}, V_{2}\right\} \geq \min \left\{\left(u_{2}^{W}\right)^{-1}\left(V_{1}-p_{1}\right), V_{2}\right\}, V_{1}-2 p_{d 1}^{O} \leq V_{1}-2 \hat{p_{1}}$, so $p_{d 1}^{O} \geq \hat{p_{1}}$.

Thus, $p_{d 1}^{O} \geq \hat{p_{1}}>p_{d 1}^{W}$.

Proof for Proposition 3 in Section 5.1. In Lemma 3, we have $\frac{2 V_{1}}{5}<p_{d 1}^{O}<\frac{V_{1}}{2}$, and $p_{m}^{O}=$ $\frac{V_{1}}{2}$. So, $\frac{4 V_{1}}{5}<p_{d 1}^{O}<p_{m}^{O}$.

$\Pi_{d 1}^{O}$ is given in Equation (5), which is price multiplying demand. See from Figure 1, the demand is smaller than $\frac{V_{1}-p_{1}}{V_{1}}$, so $\Pi_{d 1}^{O}<\frac{p_{d 1}^{O}\left(V_{1}-p_{d 1}^{O}\right)}{V_{1}}$. $\Pi_{m}^{O}=\frac{p_{m}^{O}\left(V_{1}-p_{m}^{O}\right)}{V_{1}}$. With $p_{d 1}^{O}<$ $p_{m}^{O}=\frac{V_{1}}{2}$, it is obvious that $\Pi_{d 1}^{O}<\Pi_{m}^{O}$.

Proof for Proposition 4 in Section 5.1. In Proposition 2, we have $\frac{2 V_{1}}{5}<p_{d 1}^{W}<\frac{V_{1}}{2}$, and $p_{m}^{W}=$ $\frac{V_{1}}{2}$. So, $\frac{4 V_{1}}{5}<p_{d 1}^{W}<p_{m}^{W}$.

Also, since $c_{d 1}^{W}<\frac{\delta}{4}$ and $c_{m}^{W}=\frac{\delta_{1}}{4}, c_{d 1}^{W}<c_{m}^{W}$.

Noted that $\Pi_{d 1}^{W}=\Pi_{d 1}^{O}+R_{d 1}\left(c_{1}\right), \Pi_{m}^{W}=\Pi_{m}^{O}+R_{m}(c)$ (from proof for Lemma 2) and $\Pi_{d 1}^{O}<\Pi_{m}^{O}$, if $R_{d 1}\left(c_{1}\right)<R_{m}(c)$, then $\Pi_{d 1}^{W}<\Pi_{m}^{W}$.

$$
R_{d 1}\left(c_{1}\right)=c_{1}\left(\int_{\sqrt{2 \delta_{1} c_{1}}}^{2 \delta_{1}} \min \left\{\left(u_{2}^{k}\right)^{-1}\left(\frac{v_{1}^{2}}{4 \delta_{1}}-c_{1}\right), V_{2}\right\} \frac{1}{V_{1} V_{2}} d v_{1}\right)
$$




$$
\begin{aligned}
& -c_{1}\left(\int_{0}^{\delta_{1}-c_{1}} \min \left\{\left(u_{2}^{k}\right)^{-1}\left(v_{1}\right), V_{2}\right\} \frac{1}{V_{1} V_{2}} d v_{1}\right) \\
& =c_{1}\left(\int_{\sqrt{2 \delta_{1} c_{1}}}^{2 \delta_{1}} \min \left\{\left(u_{2}^{k}\right)^{-1}\left(\frac{v_{1}^{2}}{4 \delta_{1}}-c_{1}\right), V_{2}\right\} \frac{1}{V_{1} V_{2}} d v_{1}\right) \\
& -c_{1}\left(\int_{\sqrt{2 \delta_{1} c_{1}}}^{2 \delta_{1}} \min \left\{\left(u_{2}^{k}\right)^{-1}\left(\frac{v_{1}^{2}}{4 \delta_{1}}-c_{1}\right), V_{2}\right\} \frac{1}{V_{1} V_{2}} d\left(\frac{v_{1}^{2}}{4 \delta_{1}}-c_{1}\right)\right) \\
& =c_{1}\left(\int_{\sqrt{2 \delta_{1} c_{1}}}^{2 \delta_{1}} \min \left\{\left(u_{2}^{k}\right)^{-1}\left(\frac{v_{1}^{2}}{4 \delta_{1}}-c_{1}\right), V_{2}\right\} \frac{1}{V_{1} V_{2}}\left(1-\frac{v_{1}}{2 \delta_{1}}\right) d v_{1}\right) \\
& \quad<c_{1}\left(\int_{\sqrt{2} \delta_{1} c_{1}}^{2 \delta_{1}} \frac{1}{V_{1}}\left(1-\frac{v_{1}}{2 \delta_{1}}\right) d v_{1}\right)=c_{1}\left(2 \delta_{1}-2 \sqrt{\delta_{1} c_{1}}\right)-c_{1}\left(\delta_{1}-c_{1}\right)=\left[\sqrt{c_{1}}\left(\sqrt{\delta_{1}}-\sqrt{c_{1}}\right)\right]^{2} . \\
& \text { So, } R_{d 1}\left(c_{1}\right)<\left[\sqrt{c_{d 1}^{W}}\left(\sqrt{\delta_{1}}-\sqrt{c_{d 1}^{W}}\right)\right]^{2} . R_{m}\left(c_{1}\right)=\left[\sqrt{c_{m}^{W}}\left(\sqrt{\delta_{1}}-\sqrt{c_{m}^{W}}\right)\right]^{2} . \\
& \text { Since } c_{d 1}^{W}<\frac{\delta}{4}=\left(c_{m}^{W}\right)^{*}, \text { it is obvious that } R_{d 1}\left(c_{1}\right)<R_{m}(c) .
\end{aligned}
$$

Proof for $p_{d}^{W} / c_{d}^{W}<p_{m}^{W} / c_{m}^{W}$ in Section 5.2. Let $f(c)=-\frac{\delta^{2}}{3}-\frac{8 \sqrt{\delta c^{3}}}{3}+2 \delta c+\frac{c^{2}}{2}$. Then $p_{d}^{W}=$ $\sqrt{2 V^{2}+f(c)}-V \cdot \frac{\partial f(c)}{\partial c}=c+2 \delta-4 \sqrt{\delta c} \cdot \frac{\partial^{2} f(c)}{\partial c^{2}}=1-2 \sqrt{\frac{\delta}{c}}<0 .\left.\frac{\partial f(c)}{\partial c}\right|_{c=\frac{\delta}{4}}=\frac{\delta}{4}>0$, so $f(c)$ increases in $c .\left.f(c)\right|_{c=\frac{\delta}{4}}=-\frac{13 \delta}{96}<0$.

So, $-\frac{\delta^{2}}{3}<f(c)<0$ when $c<\frac{\delta}{4}$, and $\sqrt{2 V^{2}-\frac{\delta^{2}}{3}}-V<p_{d}^{W}<(\sqrt{2}-1) V$.

Let $\frac{\partial R_{d}(c)}{\partial c}=p(\sqrt{\delta}-\sqrt{c})(\sqrt{\delta}-2 \sqrt{c})-\frac{\delta^{2}}{3}+3 c^{\frac{1}{2}} \delta^{\frac{3}{2}}-5 \delta c+\frac{13 c^{\frac{3}{2}} \delta^{\frac{1}{2}}}{3}-2 c^{2}-\delta c \ln \frac{\delta}{c}$.

We have $\frac{\partial R_{d}(c)}{\partial c}$ is positive and then negative. The optimal $c_{d}^{W}$ is at $\frac{\partial R_{d}(c)}{\partial c}=0$.

Also, with $p>\sqrt{2 V^{2}-\frac{\delta^{2}}{3}}-V>\left(\sqrt{\frac{23}{3}}-2\right) \delta$, we have $\left.\frac{\partial R_{d}(c)}{\partial c}\right|_{c=\frac{\delta}{2(\sqrt{2}+1)}}>0$, so

$$
c_{d}^{W}>\frac{\delta}{2(\sqrt{2}+1)} \text {. Thus, } p_{d}^{W} / c_{d}^{W}<\frac{\sqrt{2}-1) V}{\frac{\delta}{2(\sqrt{2}+1)}}=\frac{2 V}{\delta}=p_{m}^{W} / c_{m}^{W} \text {. }
$$

\section{References}

1. Guo, L. Service cancellation and competitive refund policy. Mark. Sci. 2009, 28, 901-917. [CrossRef]

2. Shulman, J.D.; Coughlan, A.T.; Savaskan, R.C. Managing consumer returns in a competitive environment. Manag. Sci. 2011, 57, 347-362. [CrossRef]

3. Anwar, A.; Waqas, A.; Zain, M.; Kee, D. Impact of Music and Colour on Customers' Emotional States: An Experimental Study of Online Store. Asian J. Bus. Res. 2020, 10. [CrossRef]

4. Ijaz, M.F.; Rhee, J. Constituents and Consequences of Online-Shopping in Sustainable E-Business: An Experimental Study of Online-Shopping Malls. Sustainability 2018, 10, 3756. [CrossRef]

5. Ülkü, M.A.; Gürler, A. The impact of abusing return policies: A newsvendor model with opportunistic consumers. Int. J. Prod. Econ. 2018, 203, 124-133. [CrossRef]

6. Davis, S.; Gerstner, E.; Hagerty, M. Money back guarantees in retailing: Matching products to consumer tastes. J. Retail. 1995, 71, 7-22. [CrossRef]

7. Che, Y.K. Customer return policies for experience goods. J. Ind. Econ. 1996, 44, 17-24.

8. Davis, S.; Hagerty, M.; Gerstner, E. Return policies and the optimal level of 'hassle'. J. Econ. Bus. 1998, 50, 445-460. [CrossRef]

9. Wu, M.; Teunter, R.H.; Zhu, S.X. Online marketing: When to offer a refund for advanced sales. Int. J. Res. Mark. $2019,36,471-491$. doi:10.1016/j.ijresmar.2018.11.003. [CrossRef]

10. Hess, J.D.; Chu, W.; Gerstner, E. Controlling product returns in direct marketing. Mark. Lett. 1996, 7, 307-317. [CrossRef]

11. Chu, W.; Gerstner, E.; Hess, J.D. Managing dissatisfaction how to decrease customer opportunism by partial refunds. J. Serv. Res. 1998, 1, 140-155. [CrossRef]

12. Akan, M.; Ata, B.; Dana, J.D. Revenue management by sequential screening. J. Econ. Theory 2015, 159, 728-774. [CrossRef]

13. Liu, Q.; Xiao, W. Selling to Heterogeneous Customers with Uncertain Valuations under Returns Policies. Working Paper.

14. Shulman, J.D.; Coughlan, A.T.; Savaskan, R.C. Optimal reverse channel structure for consumer product returns. Mark. Sci. 2010, 29, 1071-1085. [CrossRef]

15. Grossman, S.J. The informational role of warranties and private disclosure about product quality. J. Law Econ. 1981, 24, 461-483. [CrossRef]

16. Emons, W. The theory of warranty contracts. J. Econ. Surv. 1989, 3, 43-57. [CrossRef]

17. Moorthy, S.; Srinivasan, K. Signaling quality with a money-back guarantee: The role of transaction costs. Mark. Sci. 1995, 14, 442-466.

18. Shieh, S. Price and Money-Back Guarantees as Signals of Product Quality. J. Econ. Manag. Strategy 1996, 5, 361-377. [CrossRef]

19. Heal, G. Guarantees and risk-sharing. Rev. Econ. Stud. 1977, 44, 549-560. [CrossRef] 
20. Matthews, S.; Moore, J. Monopoly provision of quality and warranties: An exploration in the theory of multidimensional screening. Econ. J. Econ. Soc. 1987, 55, 441-467. [CrossRef]

21. Welling, L.A. Satisfaction guaranteed or money (partially) refunded: Efficient refunds under asymmetric information. Can. J. Econ. 1989, 22, 62-78. [CrossRef]

22. Padmanabhan, V.; Rao, R.C. Warranty policy and extended service contracts: Theory and an application to automobiles. Mark. Sci. 1993, 12, 230-247. [CrossRef]

23. Xie, J.; Gerstner, E. Service escape: Profiting from customer cancellations. Mark. Sci. 2007, 26, 18-30. [CrossRef]

24. Cachon, G.P. Supply chain coordination with contracts. Handb. Oper. Res. Manag. Sci. 2003, 11, $227-339$.

25. Ferguson, M.; Guide, V.D.R., Jr.; Souza, G.C. Supply chain coordination for false failure returns. Manuf. Serv. Oper. Manag. 2006, 8, 376-393. [CrossRef]

26. Xiao, T.; Shi, K.; Yang, D. Coordination of a supply chain with consumer return under demand uncertainty. Int. J. Prod. Econ. 2010, 124, 171-180. [CrossRef]

27. Su, X. Consumer returns policies and supply chain performance. Manuf. Serv. Oper. Manag. 2009, 11, 595-612. [CrossRef]

28. Pasternack, B.A. Optimal Pricing and Return Policies for Perishable Commodities. Mark. Sci. 1985, 4, 166-176. [CrossRef]

29. Li, T.; Xie, J.; Liu, X. Consumer return policies in presence of a P2P market. Omega 2020, 97, 102092. [CrossRef]

30. Huang, M.; Jin, D. Impact of buy-online-and-return-in-store service on omnichannel retailing: A supply chain competitive perspective. Electron. Commer. Res. Appl. 2020, 41, 100977. [CrossRef]

31. Jiang, B.; Tian, L. Collaborative Consumption: Strategic and Economic Implications of Product Sharing. Manag. Sci. 2018, 64, 1171-1188. [CrossRef]

32. Shanthi, R.; Kannaiah, D. Consumers' perception on online shopping. J. Mark. Consum. Res. 2015, 13, 14-21.

33. Ijaz, M.F.; Tao, W.; Rhee, J.; Kang, Y.S.; Alfian, G. Efficient Digital Signage-Based Online Store Layout: An Experimental Study. Sustainability 2016, 8, 511. [CrossRef]

34. Alfian, G.; Ijaz, M.F.; Syafrudin, M.; Syaekhoni, A.; Fitriyani, N.; Rhee, J. Customer behavior analysis using real-time data processing: A case study of digital signage-based online stores. Asia Pac. J. Mark. Logist. 2019, 31, 265-290. [CrossRef]

35. Wagner, G.; Schramm-Klein, H.; Steinmann, S. Online retailing across e-channels and e-channel touchpoints: Empirical studies of consumer behavior in the multichannel e-commerce environment. J. Bus. Res. 2018, 107, 256-270. [CrossRef] 